\title{
BALANÇO E PERSPECTIVAS DA PÓS-GRADUAÇÃO EM GEOGRAFIA NO BRASIL - CONSIDERAÇÕES SOBRE A AVALIAÇÃO TRIENAL DE 2010/2012
}

\author{
Balance and perspectives in geography postgraduation in Brazil - \\ consideration of the triennial assessment 2010/2012
}

Balance y perspectivas del posgrado en geografía en Brasil -
consideraciones con respecto a la evaluación trienal 2010/2012

\section{João Lima Sant'Anna Neto}

Professor Titular do Departamento de Geografia da UNESP/Presidente Prudente. Coordenador da Área de Geografia na Capes (2011-2014) e Coordenador Adjunto (2008-2011).E.mail: joaolima@fct.unesp.br

\section{Márcio Piñon de Oliveira}

Professor Doutor do Departamento de Geografia da Universidade Federal Fluminense. Coordenador Adjunto da Área de Geografia (2011-2014).E.mail: marpinon.oliveira@gmail.com

\section{RESUMO}

Este artigo apresenta um balanço da pós-graduação em Geografia no Brasil, por meio de um resgate histórico da institucionalização da CAPES, como órgão responsável pelo estabelecimento de política pública de gestão e financiamento do sistema nacional de pós-graduação. Considerando este marco legal, o objetivo deste texto é o de demonstrar e discutir os critérios envolvidos no processo de avaliação, no contexto dos avanços que permitiram à área de Geografia implementar uma série de inovações no sentido de se construir uma avaliação pautada em aspectos qualitativos e adequados para a cultura acadêmica das ciências humanas. Utilizando-se do banco de dados da Capes (Geocapes) e dos relatórios trienais da avaliação de 2010/2012, apresentam-se e discutem-se os quesitos e itens constantes do processo de avaliação, a partir do qual, apontam-se os avanços alcançados, as limitações que ainda se impõem e os problemas a serem enfrentados. Conclui-se que a área de Geografia avançou quantitativamente e distribuiu-se pelo território brasileiro, permitindo a descentralização da formação de mestres e doutores. Por outro lado, o principal desafio a ser enfrentado é o de continuar se qualificando até atingir um nível de maturidade acadêmica que possibilite alcançar um estágio de excelência.

PALAVRAS CHAVE: avaliação, pós-graduação em geografia, perspectivas da geografia, Capes 


\section{ABSTRACT}

This article presents a graduate balance of Brazilian Geography, through a historical review of CAPES institutionalization, as the responsible for public policy establishment of management and financing national postgraduate system. Considering this legal framework, the aim of this paper is to demonstrate and discuss the criteria involved in the evaluation process, in the context of the advances that have enabled the field of Geography implement a number of innovations in order to build an assessment guided by qualitative aspects and suitable for the academic culture of the humanities. Using the database of the Capes (Geocapes) and evaluation of triennial reports of 2010/2012, we present and discuss the results and questions contained in the evaluation process items, from which, it was pointed out advances achieved, the limitations that still impose and the problems to be faced. It follows that the field of Geography quantitatively advanced and distributed by the Brazilian territory, allowing the decentralization of training masters and doctors. On the other hand, the main challenge to be faced is to continue to qualify to a level of academic maturity that allows reach a stage of excellence. KEYWORDS: evaluation, graduate in geography, geography perspective, Capes

\section{RESUMEN}

En este artículo se presenta un balance del posgrado en Geografía en Brasil, a través de una revisión histórica de la institucionalización de la CAPES, como el órgano encargado de establecer la política pública de la gestión y la financiación del sistema nacional de posgrado. Teniendo en cuenta este marco legal, el objetivo de este trabajo es demostrar y discutir los criterios que intervienen en el proceso de evaluación, en el contexto de los avances que han permitido que el campo de la Geografía introducir una serie de innovaciones con el fin de construir una evaluación guiada por aspectos cualitativos y adecuados para la cultura académica de las humanidades. Utilizando la base de datos de la CAPES (Geocapes) y la evaluación de los informes trienales de $2010 / 2012$, se presentan y discuten los resultados y las preguntas contenidas en los criterios del proceso de evaluación, a partir del cual, se señaló los avances logrados, las limitaciones que todavía se imponen y los problemas que hay que afrontar. De ello se desprende que el campo de la geografía cuantitativamente avanzó y se distribuye por el territorio nacional, lo que permite la descentralización de la formación de maestros y doctores. Por otra parte, el principal desafío a enfrentar es seguir para calificar a un nivel de madurez académica que permite llegar a una etapa de excelencia.

PALABRAS CLAVE: evaluación, postgrado en geografía, perspectiva geografía, CAPES 


\section{APRESENTAÇÃO}

Uma das grandes dificuldades de qualquer atividade de coordenação e de gestão no mundo acadêmico é a de compatibilizar as demandas e anseios da comunidade na qual se insere, com as políticas estabelecidas em esferas hierarquicamente superiores.

A Capes, por determinação constitucional é o órgão responsável pela política nacional de pós-graduação, por sua gestão e financiamento. O governo federal, por meio do Ministério da Educação tem estabelecido uma política de expansão do sistema nacional, aumentando o orçamento do órgão, desde 2002 e mais significativamente desde 2008, de forma a garantir esta expansão.

O presente artigo se dispõe traçar os contornos do quadro atual da Pós-Graduação, no âmbito da Geografia, com base no resultado da avaliação trienal 2010/2012 e seus principais indicadores.

Depois de muito nos debatermos contra e diante do sistema de avaliação da CAPES, quer por falta de cultura, ausência de informações mais precisas ou mesmo por pura e simples rebeldia a tudo que vem de fora, nos tira da posição de conforto e alude a alguma forma de controle, parece que a comunidade geográfica toma consciência da sua importância e participação nesse processo como forma de organização e fortalecimento coletivo e institucional dos seus programas.

No cômputo geral, temos utilizado a avaliação, com todas as críticas e imperfeições que ainda lhe são passíveis, para o crescimento e aperfeiçoamento da área de geografia, da sua produção intelectual, cooperação internacional e democratização da formação e da pesquisa, com a expansão e surgimento de programas em regiões e centros longínquos, até então, despovoados de programas ou inteiramente fora de contexto. Conseguimos alcançar na década de 2000 a presença de programas em todas as regiões do Brasil e no último triênio (2010/2012) tivemos o aumento de programas no interior do país, com o surgimento, inclusive, dos primeiros programas no interior do Nordeste, a saber, na UVA, em Sobral, no estado do Ceará e na UEFS, em Feira de Santana, na Bahia ${ }^{1}$.

O Mestrado Acadêmico em Geografia da UVA - Universidade Estadual Vale do Acaraú (CE) - teve a sua criação aprovada pela CAPES em março de 2012 e o Programa de Pós-Graduação em Planejamento Territorial - Mestrado Profissional - da Universidade Estadual de Feira de Santana (UEFS/BA), em 2013. 


\section{CONTORNOS INICIAIS}

Na origem, o germe da Pós-Graduação em Geografia tem quase o tempo da nossa geografia oficial do IBGE (1937) ${ }^{2}$ e da primeira divisão regional do Brasil e do planejamento institucional (1942) ${ }^{3}$. Foi ainda no início da década de 1930 que, por iniciativa de Francisco Campos, na época Ministro da Educação e Saúde Pública, foi instituída no Brasil a “investigação científica em quaisquer domínios dos conhecimentos humanos" como finalidade do ensino universitário, através do decreto n 19.851 , de abril de $1931^{4}$.

Segundo Cury (2005), "esse decreto institucionaliza também cursos de aperfeiçoamento e de especialização como forma de aprofundamento de conhecimentos profissionais e científicos", assim como estabelece, no seu art. 32, que "nos institutos universitários será atendido há um tempo o duplo objetivo de ministrar o ensino eficiente dos conhecimentos humanos adquiridos e de estimular o espírito de investigação original, indispensável ao progresso das ciências". O título de doutor, expresso no art. 90, devia se apoiar em uma tese, do que resultaria tanto a expedição de um diploma quanto à assinalação de uma dignidade honorífica.

Assim, o decreto $\mathrm{n}^{\circ} 19.851$ conferira as universidades nascentes o duplo atributo de lugares realizadores de pesquisas e, ao mesmo tempo, de lugares formadores de pesquisadores e doutores em ciências. Nesse sentido, estaria aí a certidão de nascimento da nossa pós-graduação, uma vez que o decreto cola, desde a origem da institucionalização do ensino superior, a investigação científica, a saber, a pesquisa, nos seus diferentes domínios, com a finalidade de ensino dos institutos universitários.

O surgimento da CAPES (Coordenação de Aperfeiçoamento do Pessoal de Nível Superior) em 1951, pelas mãos de Anísio Teixeira, seu primeiro presidente, viria dar corpo a essa política de estado, institucionalizando e organizando a pesquisa no interior das universidades e demais instituições de ensino superior ${ }^{5}$. Contudo, a consolidação do regulamento da pós-graduação só viria na década seguinte com o Parecer Conselho Federal de Educação n 977/65, concedendo a CAPES novas atribuições e meios orçamentários ${ }^{6}$.

\footnotetext{
A criação do IBGE em 1937 incorporou o Instituto Nacional de Estatística (INE), criado em 1934 e que iniciou suas atividades em 29 de maio de 1936, e o Conselho Brasileiro de Geografia, de 1936. IANNI, Octavio. Estado e Planejamento Econômico no Brasil (1930-1970). Rio de Janeiro: Civilização Brasileira (3a ed.). 1979. p. 23.

3 A primeira divisão regional oficial do Brasil foi realizada pelo IBGE no final da década de 1930, e se institucionalizou a partir da Circular No. 1 de 31 de janeiro de 1942 da Secretaria da Presidência da República. O principal articulador e teórico da divisão foi Fabio Macedo Soares Guimarães, então Chefe da Divisão de Geografia do Conselho Nacional de Geografia do IBGE.Desde o final da década de 1930 o IBGE - através da ação do Conselho Nacional de Geografia - vinha promovendo debates internos e tentativas de influenciar as decisões federais relativas à organização do território brasileiro em novos moldes (Magnano, 1995). Segundo Manuel Correia de Andrade (1977, p. 9), nesta época o IBGE seria o "grande centro de estudos geográficos no Brasil". (CONTEL, Fábio B. As Divisões Regionais do IBGE no século XX (1942, 1970 e 1990). Terra Brasilis. Nova Série, n. 3, 2014)

4 Cf. Cury, 2005, p.8

5 Cf. Silva, J.B. e Oliveira, M.P., 2009

6 Cf. Cury, 2005, p.11
} 
Muito embora a legislação já concedesse título de doutor e livre docência a pesquisadores eméritos que submetiam seus trabalhos publicamente a uma defesa de tese, os cursos de mestrado e doutorado nas universidades brasileiras só se desenvolveriam, a partir da polêmica Reforma Universitária de 1968, em pleno regime militar que, contraditoriamente, daria ênfase a pós-graduação. O nascimento dos cursos de pós-graduação na Universidade de São Paulo (USP), a partir de 1969, é um exemplo desse contexto ${ }^{7}$. A Geografia teve os seus primeiros cursos estimulados exatamente por essa conjuntura. Assim, a primeira pós-graduação em Geografia foi a da USP, ciada em 1971 e dividida em dois programas: Geografia Física e Geografia Humana, ambos com cursos de mestrado e doutorado. Nessa mesma década seriam criados ainda os Programas de Pós-Graduação da Universidade Federal de Pernambuco (UFPE), em 1976, e o da Universidade Estadual Paulista (UNESP/RC), em Rio Claro, no ano de 1977; ambos com o Curso de Mestrado ${ }^{8}$.

É da década de 1970 também o surgimento das primeiras Associações Científicas de Pós-Graduação voltadas para os interesses específicos de suas respectivas áreas. Dentre elas, encontram-se a pioneira ANPEC (Economia), a ANPOCS (Política e Ciências Sociais), ANPAD (Administração) ${ }^{9}$. A ANPEGE (Geografia) nasceria somente duas décadas depois, em 1994, com a expansão dos cursos na área. Inicialmente o debate sobre a produção da pesquisa e a pós-graduação na Geografia convergiu para a Associação de Geógrafos Brasileiros (AGB), que desempenharia o importante papel de espaço de intercâmbio acadêmico independente dos quadros institucionais, encaminhando suas opiniões e posicionamentos de modo crítico ante as políticas governamentais específicas para área e repercussão para o contexto mais geral que se inserem.

Se a década de 1970 foi a da forte institucionalização da CAPES e afirmação do seu papel como órgão de estímulo à formação em nível superior, a década de 1980 foi a do estabelecimento de instrumentos que fortaleceram e consolidaram a ação da CAPES como órgão reitor da pós-graduação no Brasil. O decreto n 86.816, de 05/01/1982, "ampliou as funções da CAPES concedendo a ela mais autonomia e poderes no tocante à elaboração e

\footnotetext{
"Os cursos de pós-graduação na USP, no formato que existem hoje, iniciaram-se em 1969, quando o MEC promoveu a criação oficial dos cursos de pós-graduação no Brasil. Entretanto, a formação de doutores pela Universidade de São Paulo é anterior à iniciativa do governo federal. A primeira tese de doutorado em Geografia foi defendida em 1944." Os primeiros doutores foram os professores Ary França (1944) e Maria da Conceição Vicente de Carvalho (1945). In: http://www.geografia.fflch.usp.br/posgraduacao, acesso em 31/03/2015.

8 "De acordo com Barros (1998, p.133), os fatores que contribuíram para o fenômeno expansionista da pós-graduação, a partir de meados da década de 1970, foram: a exigência de titulação pós-graduada para a progressão na carreira do magistério superior; a necessidade de formação de pesquisadores para a ciência nacional (em especial para os grandes projetos de desenvolvimento do país); prestígio dos cursos de mestrado e doutorado para as universidades (status e recursos financeiros); pressão dos novos mestres e doutores que, em suas instituições de origem, desejam fomentar um ambiente favorável às atividades docentes e de pesquisa; o próprio I PNPG (Plano Nacional de Desenvolvimento da Pós-Graduação), ao fixar metas para a titulação de novos mestres e doutores”. In: Silva, J.B. e Oliveira, M.P. (2009).

9 Cf. Córdovaet alii, 1986, p. 53
} 
ao estabelecimento da política de pós-graduação, bem como à coordenação, ao acompanhamento e avaliação dos programas em nível nacional. Sua estrutura básica é mantida, desde essa época, até os dias atuais, na qual a avaliação se constitui em sua espinha dorsal, compondo um de seus setores denominado Diretoria de Avaliação"10.

Na década de 1980, sugiram no âmbito da Geografia mais quatro Programas de Pós-Graduação com o Curso de Mestrado, foram eles: Universidade Estadual de Campinas - UNICAMP (1983); Universidade Federal de Santa Catarina — UFSC (1985); Universidade Federal de Sergipe — UFSE (1985); Universidade Federal de Minas Gerais — UFMG (1988); Universidade Estadual Paulista — Campus Presidente Prudente — UNESP/PP (1988); e um Programa apenas com o Curso de Doutorado, o segundo no país depois da USP (1971), que foi a Universidade Estadual Paulista — Rio Claro — UNESP/RC (1983).No final dos anos 1980, tínhamos na área de Geografia no país 9 Cursos de Mestrado e 3 de Doutorado, tendo dobrado o número de cursos da década anterior, com uma visível concentração geográfica na Região Sudeste. Apenas os Programas de Pós-Graduação em Geografia da UFPE, da UFSE e da UFSC se situavam em outras regiões fora do Sudeste. (Silva, J.B. e Oliveira, M.P., 2009)

Comparado com os anos de 1980, a década de 1990 foi marcada pela busca de um aperfeiçoamento do sistema de avaliação e acompanhamento, sobretudo a partir de 1995, com maior centralização da CAPES e coordenação das diversas instâncias da pós-graduação. Dentre as ações/medidas adotadas encontram-se o estabelecimento de parâmetros nacionais, comuns a todos os programas de todas as áreas, o sistema qualis e a classificação por meio de conceitos. Essas ações culminam com a implantação, a partir de 1998, do sistema de avaliação trienal.

De acordo com Silva e Oliveira (2009):

Esse “aperfeiçoamento" do sistema de avaliação acabou por gerar, necessariamente, pela forma como se realizou, uma acentuada competição entre os programas de pós-graduação, na qual o dado quantitativo tende a se sobrepor ao qualitativo, e tensionar, em muitos níveis e graus, as relações: entre os diferentes programas de uma mesma área; entre estes e a CAPES; entre os colegas e pesquisadores dos diferentes programas; e, finalmente, entre as diferentes áreas do conhecimento entre si, num jogo, mais político do que acadêmico, por posições, colocando o debate sobre o produtivismo na ordem do dia.

Tudo isto na verdade está antenado com o modelo norte americano de avaliação que estabelece mérito a quem mais produz e é fortemente marcado pela utilização da mensuração na avaliação, incorrendo na tentativa de racionalização e padronização do ensino ${ }^{11}$.

\footnotetext{
${ }^{10}$ Cf. Silva, J.B. e Oliveira, M.P., 2009. Dentre alguns pontos a destacar, o Decreto 86.816 estabelece como funções da CAPES: I- acompanhar e avaliar os cursos de pós-graduação e a interação entre ensino e pesquisa; II- elaborar o Plano Nacional de Pós-Graduação bem como acompanhar e coordenar a sua execução; VIII- manter intercâmbio e contato com outros órgãos da administração pública ou com entidades privadas, inclusive internacionais e estrangeiras, visando à celebração de convênios, acordos,contratos e ajustes relativos à pós-graduação e aperfeiçoamento de pessoal de nível superior (...) (Apud Cury, 2005, p. 10).

${ }^{11}$ Cf. Souza, S. Z. L. Diferentes Visões sobre a educação. Educação Pública.Avaliação Formativa: Revendo decisões e ações educacionais.http://www.educacaopublica.rj.gov.br/oficinas/ed_ciencias/avaliacao/avaliacao_historia02.html, acesso em 21/04/2015.
} 
Chegamos aos anos 2000 com o grande desafio em lidar com a competição entre os programas e enfrentar o dilema da produtivismo no interior de cada área do conhecimento, sob pena de vermos corroer a qualidade acadêmica e a seriedade científica.

$\mathrm{Na}$ contraposição do chamado produtivismo, encontra-se uma grande maioria de docentes/pesquisadores que tem buscado se qualificar cada vez mais e ampliar meritória e qualitativamente a sua produção científica. Tal fato tem se evidenciado na ampliação do número de periódicos na área de geografia, bem como na busca da melhoria de suas qualidades na última década.

\section{A PÓS-GRADUAÇÃO NO BRASIL - EVOLUÇÃO RECENTE}

Os números da pós-graduação brasileira ainda são ínfimos. Enquanto países como a Suíça, a Alemanha ou o Reino Unido apresentam mais de 300 doutores titulados por milhão de habitantes por ano, no Brasil, não chega a 60.Do total da população brasileira (censo de 2010), 50,24\% não tem instrução ou tem apenas o ensino fundamental incompleto. Outros 7,9\% da população temo ensino superior completo.Do total de brasileiros, somente $0,32 \%$ são mestres e $0,12 \%$ são doutores (ou seja, menos de $5 \%$ dos que tem curso superior prosseguiram na pós-graduação).

Se admitirmos que para o desenvolvimento social, econômico e tecnológico, uma nação precisa ter uma população com instrução e com adequados níveis de qualificação profissional, estes números são alarmantes.

Assim, por mais que os recursos alocados tenham crescido mais do que o triplo do que os outros investimentos federais e, o pessoal titulado tenha quintuplicado no sistema nacional de pós-graduação, no período entre 1998 e 2012, sabemos que ainda é pouco e que muito há no que avançar.

Mas, é importante lembrar que,se o orçamento para financiar o sistema depende de política governamental, o centro de decisão sobre como e quanto crescer e, mais ainda, sobre os critérios de qualidade que balizam esta política, é o Conselho Técnico Científico da Capes (CTC), formado pelos coordenadores das 48 áreas de avaliação (entre elas, a da Geografia) e pelos representantes doFórum dos Pró-Reitores de Pesquisa e Pós-graduação e da Associação Nacional de Estudantes de Pós-graduação.

Se a Capes é que estabelece a política nacional, é o CTC que define a avaliação. Poucas são as áreas nas quais os coordenadores se colocam como sujeitos políticos e mediadores entre as demandas de suas comunidades e as ações políticas do governo federal, do MEC e da Capes. Afinal, os coordenadores são escolhidos por suas respectivas comunida- 
des, por meio de votação, num universo constituído por todos os programas de pós-graduação. Assim, a nosso ver, o problema maior é o da representação.

Muitos foram os avanços, desde 1998, quando o sistema nacional de pós-graduação no Brasil, através da Capes, estabelece uma nova política de gestão, acompanhamento e financiamento, até 2012, quando se completa o quinto triênio de avaliação, a despeito das críticas que se possam tecer sobre o sistema.

A falta de pessoal qualificado e as assimetrias regionais existentes no território brasileiro exigiram, naquela ocasião, uma tomada de decisão do governo federal, no sentido de promover um crescimento no número de programas, na titulação de mestres e doutores e numa política de financiamento que privilegiasse a qualidade.

Nos 15 anos que se seguiram, mais lentamente no Governo FHC (1998/2002) e mais rapidamente nos Governos Lula (2002/2010) e Dilma (2010 até o presente), o aumento dos investimentos em bolsas de estudo e de recursos para o funcionamento dos programas e cursos de pós-graduação foi significativo, acima de qualquer outro investimento no plano educacional (ainda que se avalie que o ensino básico seja prioritário).

De 2002 até 2007, o investimento da Capes com bolsas de estudos, girava em torno dos R \$ 500 milhões. Em 2008 verificou-se o primeiro grande salto, quando os recursos subiram para cerca de $\mathrm{R} \$ 800$ milhões, significando aumento do valor e do número de bolsas. Em 2010, o orçamento para pagamento de bolsas praticamente dobrou, chegando a quase R \$ 1,5 bilhão. Em 2012, observou-se novamente um aumento bastante significativo, quando o investimento em bolsas ultrapassou os R \$2,1 bilhão(figura 1).

O número de cursos e programas de pós-graduação também teve aumento extraordinário. Entre 1998 e 2012, mais do que dobrou, passando de 2.049 para pouco mais de 5.000. O aumento mais significativo foi o de mestrados profissionais, nova modalidade de formação de recursos humanos em nível stricto sensu (figura 2). Neste período de uma década e meia, enquanto o número de cursos e programas dobrou, o financiamento da Capes em bolsas de estudo quintuplicou. 
Fig.1. Investimento da Capes em bolsas de estudos no Brasil (em milhões de reais).

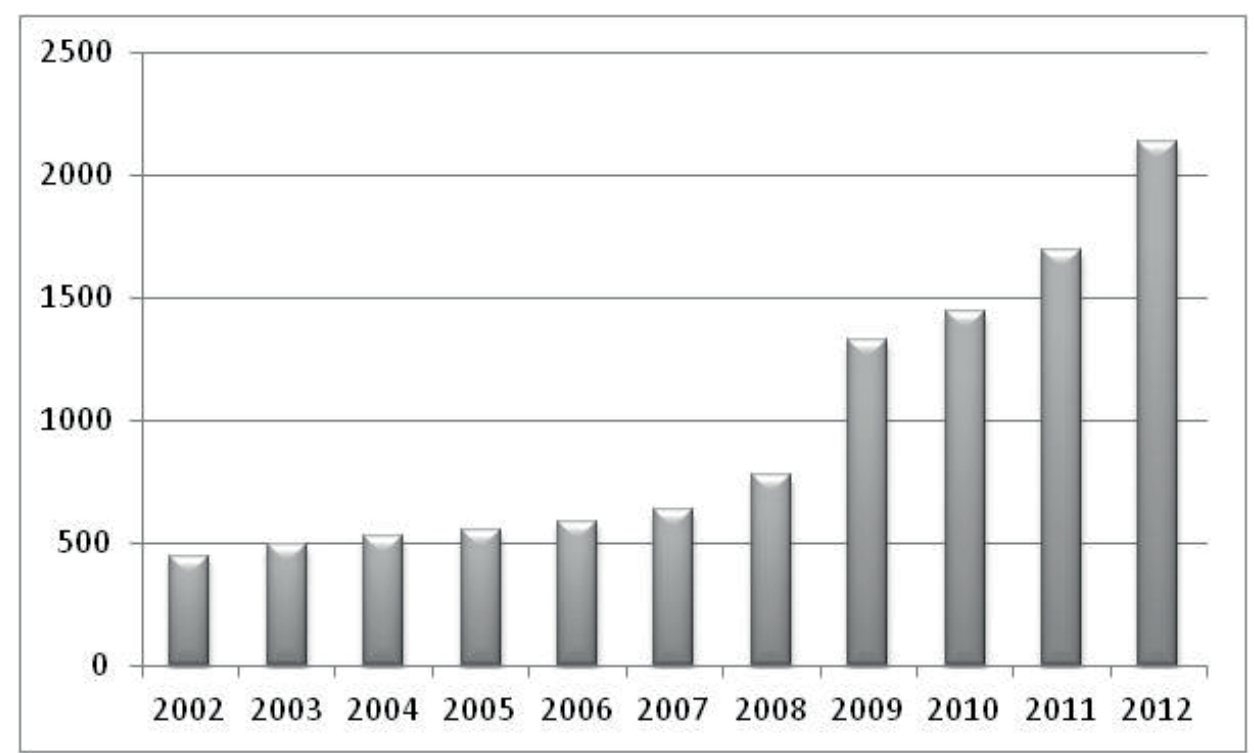

Fonte: Geocapes, 2013.

Fig.2. Número de programas de pós-graduação no Brasil (todas as áreas).

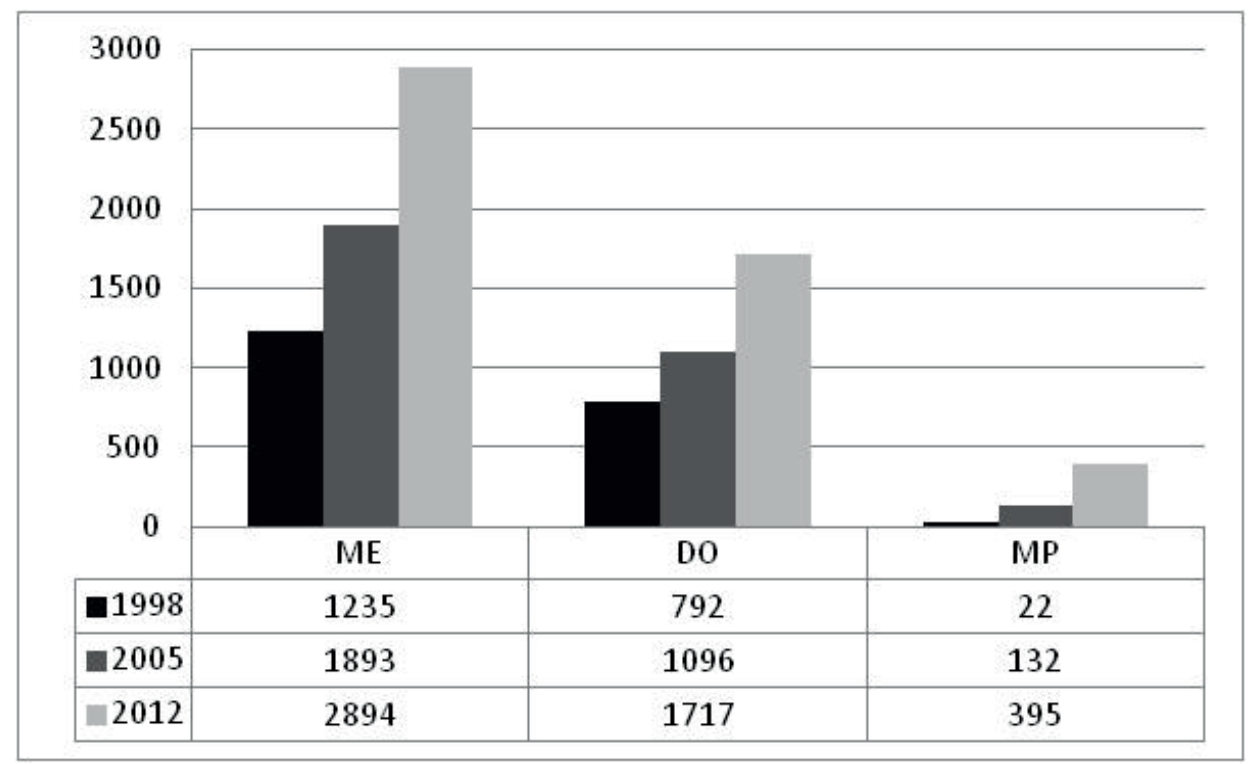

Fonte: Geocapes, 2013.

A Área de Geografia, assim como a maioria das áreas de avaliação da Capes, apresentou rápida expansão tanto do número de cursos de mestrado e doutorado, quanto da interiorização dos mesmos no território brasileiro. Em 1971, havia apenas 2 programas no País; em 2014, há 56 cursos de mestrado 2 dos quais, são mestrados profissionais e 29 cursos de doutorado, como se observa na Figura 3. 
Fig. 3. Número de programas de pós-graduação em Geografia no Brasil.

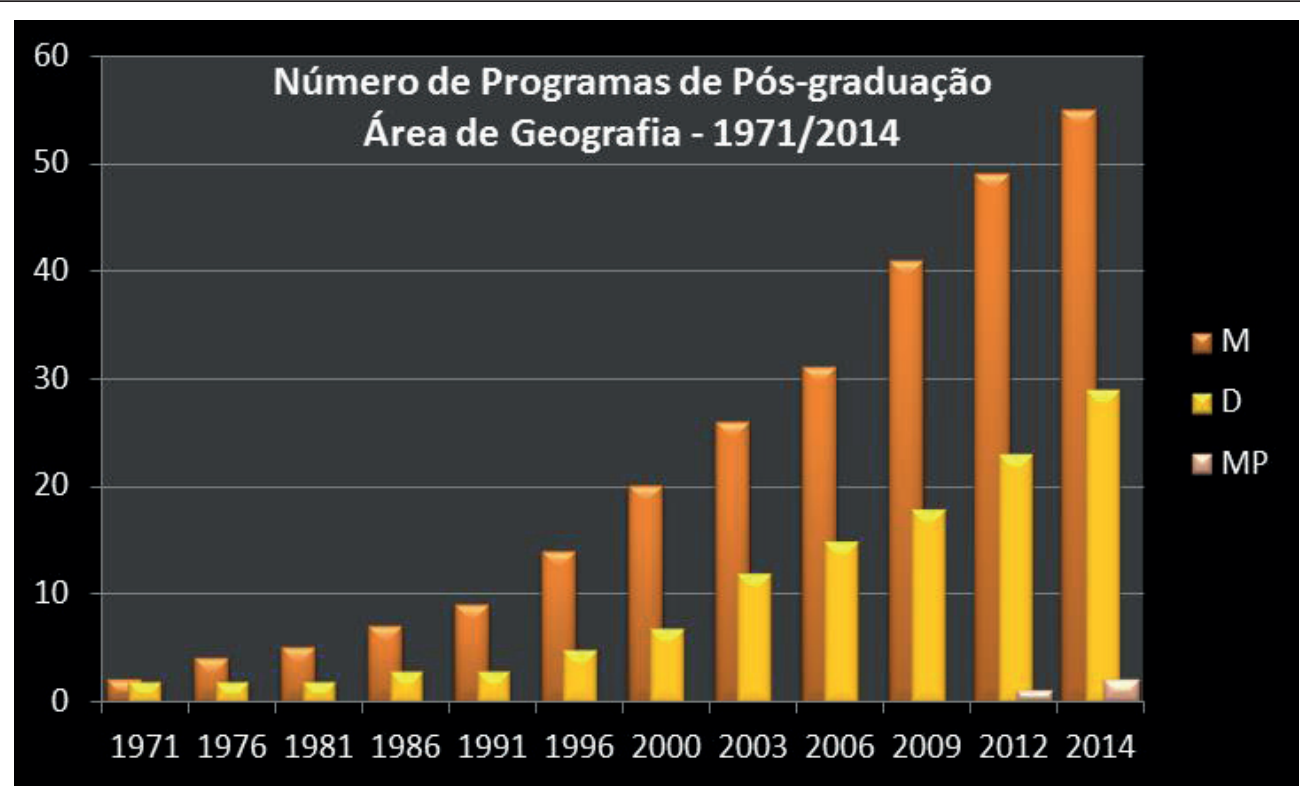

Fonte Geocapes, 2014

Nas décadas de 1970 até 1990, à partir de São Paulo, os programas de pós-graduação expandiram-se, principalmente, pelo Brasil litorâneo em estados das regiões Sudeste, Nordeste e Sul. No início do século XXI, verificou-se uma significativa expansão dos programas para a Região Centro Oeste e para o interior do país. No final da década foi avez da Região Norte.

Em 2014, apenas nos estados do Acre, Amapá e Maranhão não existiam programas de pós-graduação em Geografia (figura 4).

Fig.4.Evolução temporal e espacial dos programas de pós-graduação em Geografia - 1970/2014
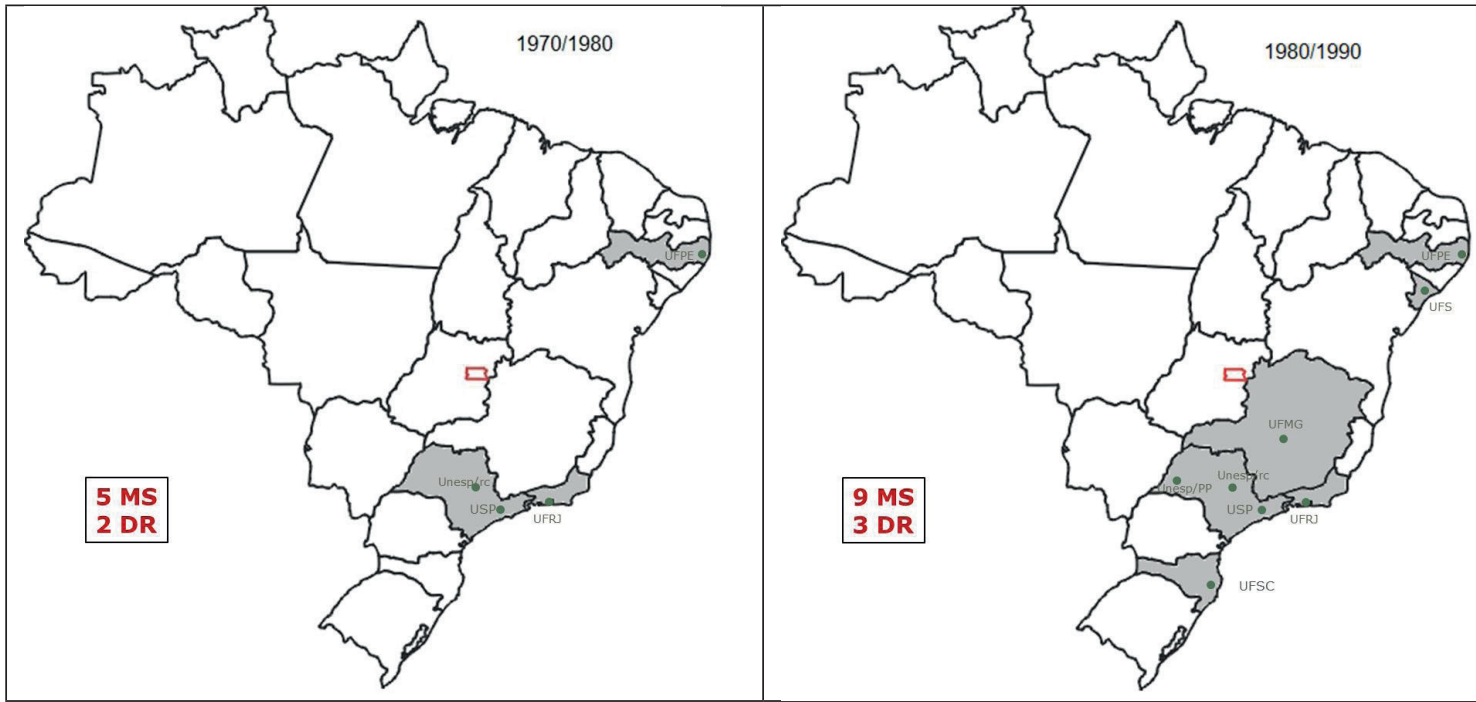

a Revista da Associação Nacional de Pós-graduação e Pesquisa em Geografia (Anpege). 


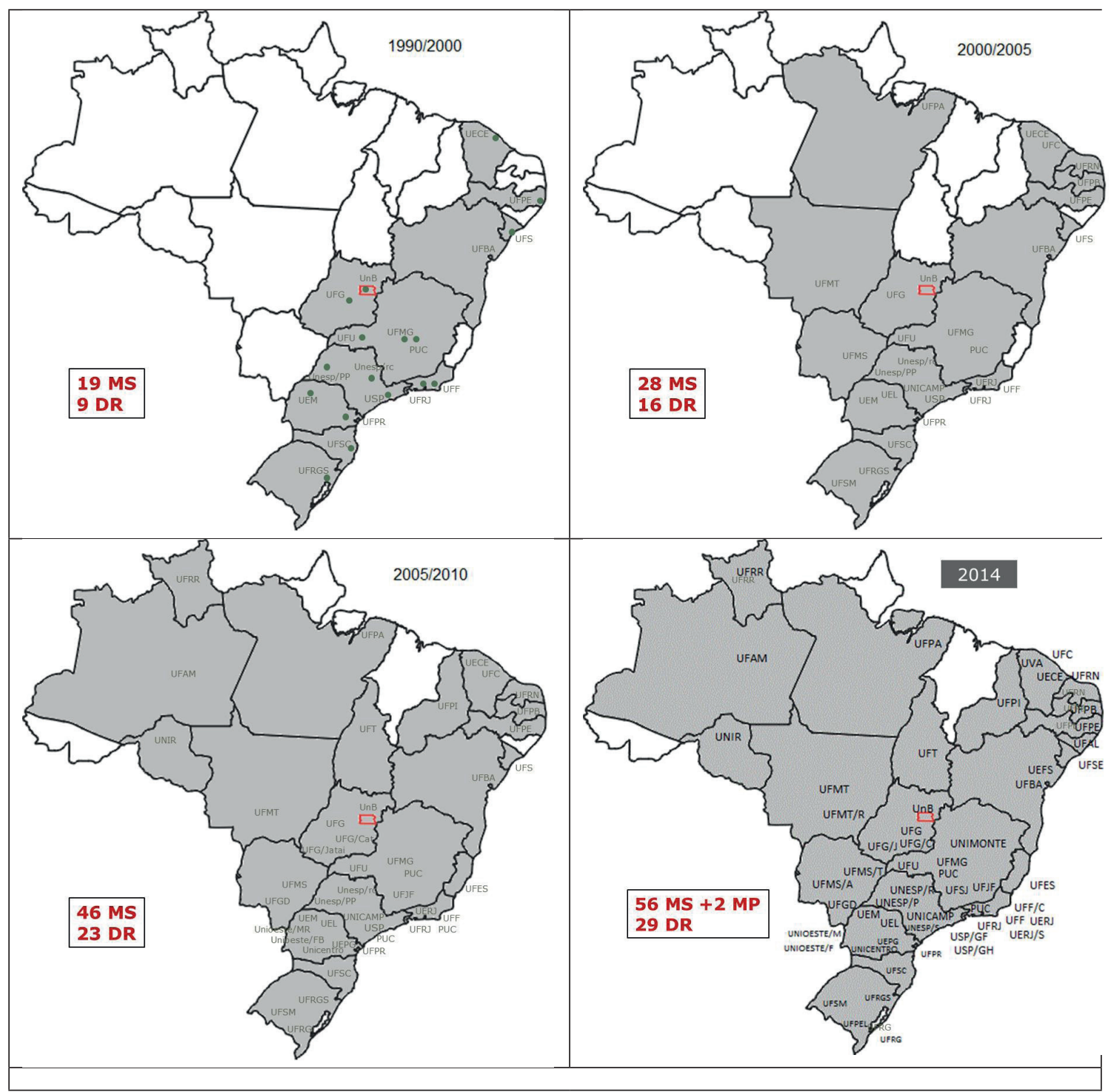

Por trás dos dados apresentados nas figuras 3 e 4, entretanto, ainda há um enorme desequilíbrio regional. Em toda a região Norte, não há nenhum programa de doutorado e, todos os 5 cursos, foram avaliados com nota inferior a 4. Na região Centro Oeste, dos 9 cursos, 3 também oferecem o nível de doutorado, mas apenas 1 tem o nível de excelência. Na região Nordeste, dos 11 cursos, apenas 2 apresentam a nota 5, ainda que7 ofereçam o nível do doutorado. Na região Sul, há 12 cursos, dos quais 7 oferecem o doutorado, mas somente 2 tem nota 5 e apenas 1 com nível de excelência.

A grande concentração de cursos com nota 5 ou superior, ocorre na região Sudeste. Dos 14 programas nesta situação, 10 estão na região (72\% do total), onde também se localizam todos os 4 programas de excelência (figura 5) 
Fig.5. Distribuição dos programas de pós-graduação em Geografia no Brasil, por região geográfica e por nota de avaliação nos últimos 4triênios $(2001 / 03,2004 / 06,2007 / 09$ e 2010/12)
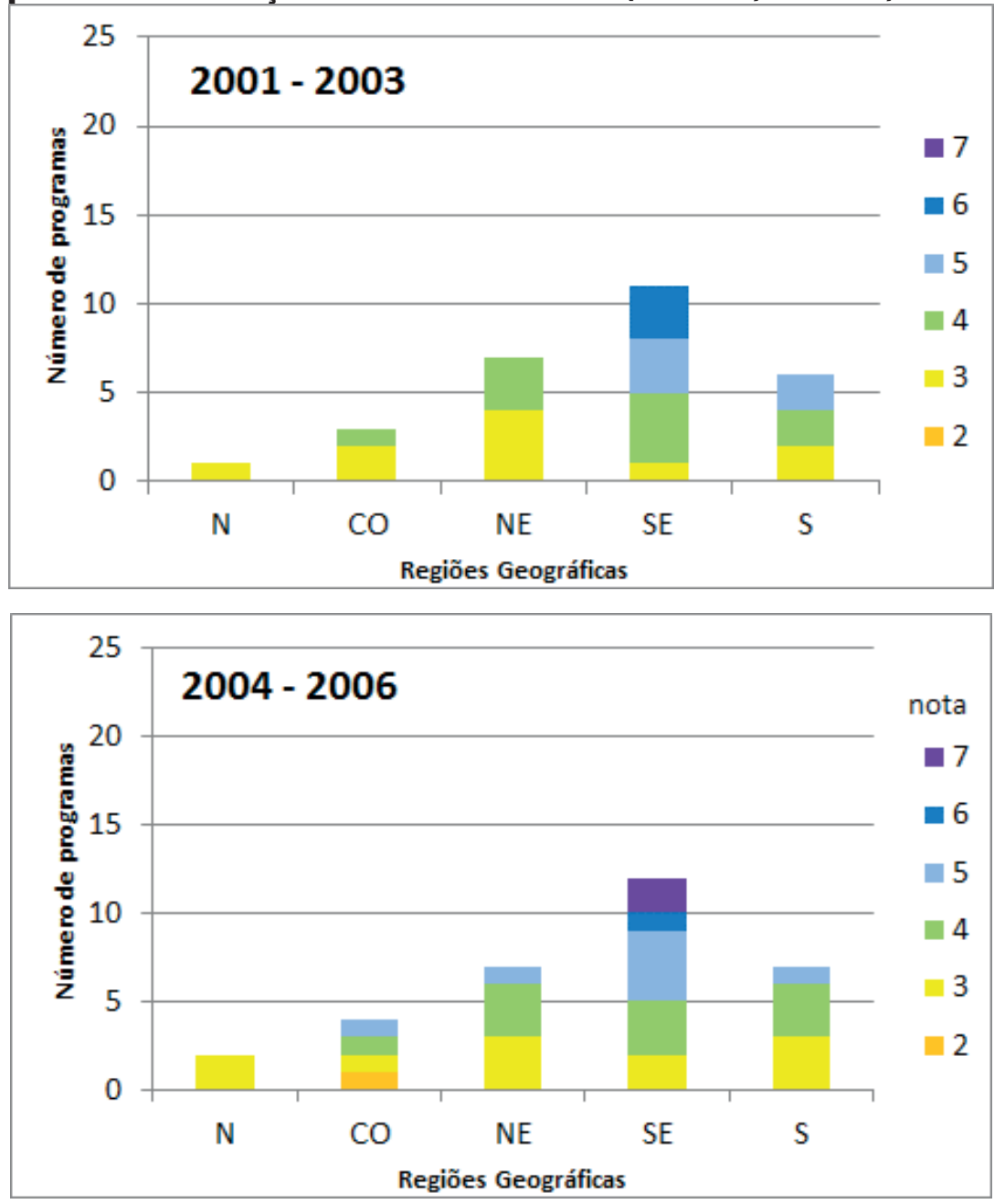

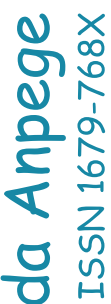

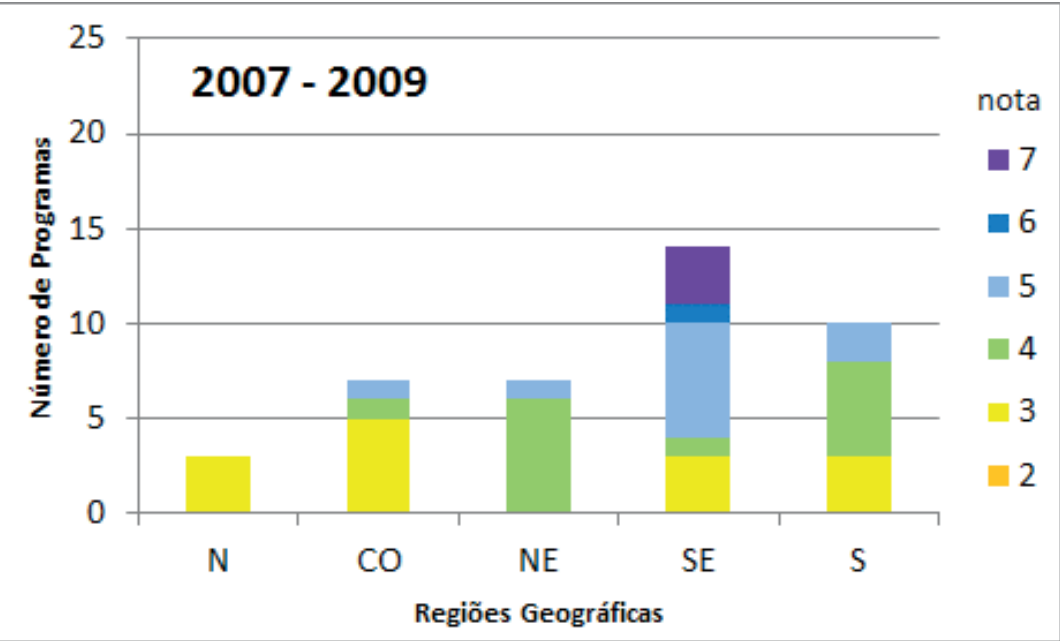

a 


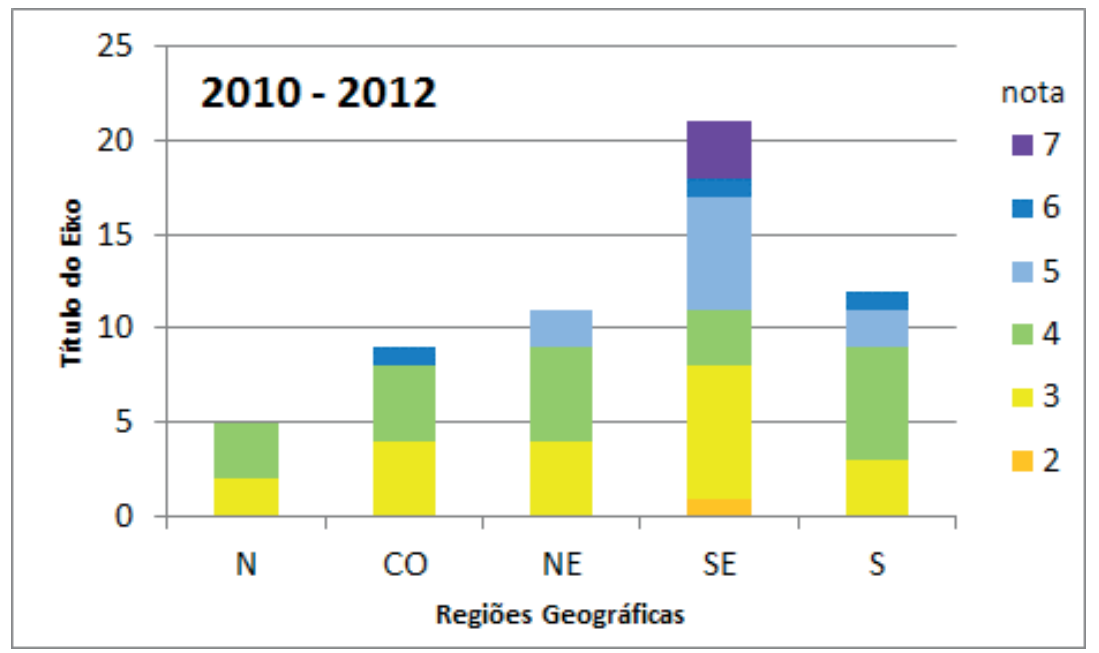

Um dos fatores que ajuda a explicar esta distribuição dos programas por região e por nota de avaliação é a própria história econômica e social do país, em que a fachada atlântica e, mais especificamente, os estados de São Paulo, Rio de Janeiro e Minas Gerais tiveram papel protagonista no desenvolvimento econômico. Assim, bastante associada à antiguidade de titulação dos doutores e criação dos departamentos de Geografia e, posteriormente, os programas de pós-graduação.

Todos os programas criados antes de 2000 apresentam nota igual ou superior a 4 e, a grande maioria dos programas nota 3, tem menos de 10 anos de existência. Ou seja, ainda não alcançaram maturidade intelectual, pois, em geral são formados por jovens doutores, mas que apresentam forte tendência de melhoria da avaliação com o tempo.

Assim, como o sistema nacional de pós-graduação cresceu fortemente na última década, o número de programas nota 3 e 4 são amplamente majoritários, porém, significando mais a juventude do programa e dos docentes, do que necessariamente a qualidade intelectual existente.

\section{Corpo Docente}

Na última avaliação trienal (2010/2012) cerca de 920 docentes estavam credenciados nos programas de pós-graduação. Destes, cerca de 730 compunham o núcleo principal, formado por docentes permanentes (figura 6). 
Fig.6. Evolução do número de docentes credenciados nos programas de pós-graduação.

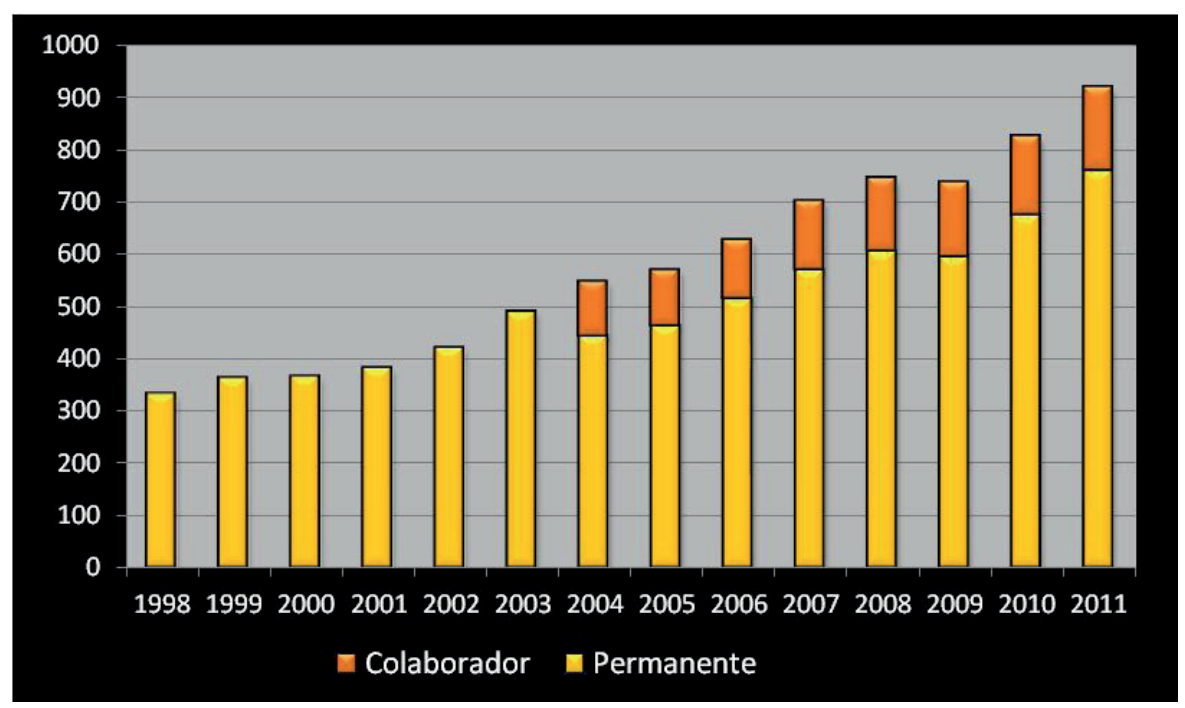

Fonte Geocapes, 2013

A área de Geografia apresenta um perfil em que 63\% dos docentes titularam-se em Geografia, nos 16 programas com nível de doutorado. Outros 28\%, obtiveram seus doutorados em outras áreas do conhecimento e, 9\% titularam-se no exterior, notadamente, na França, Espanha, Estados Unidos, Inglaterra e Alemanha (figura 7).

\section{Fig.7. Titulação dos docentes credenciados nos Programas de Geografia}

\section{-Geografia/Brasil घOutras Áreas/Brasil}

Exterior
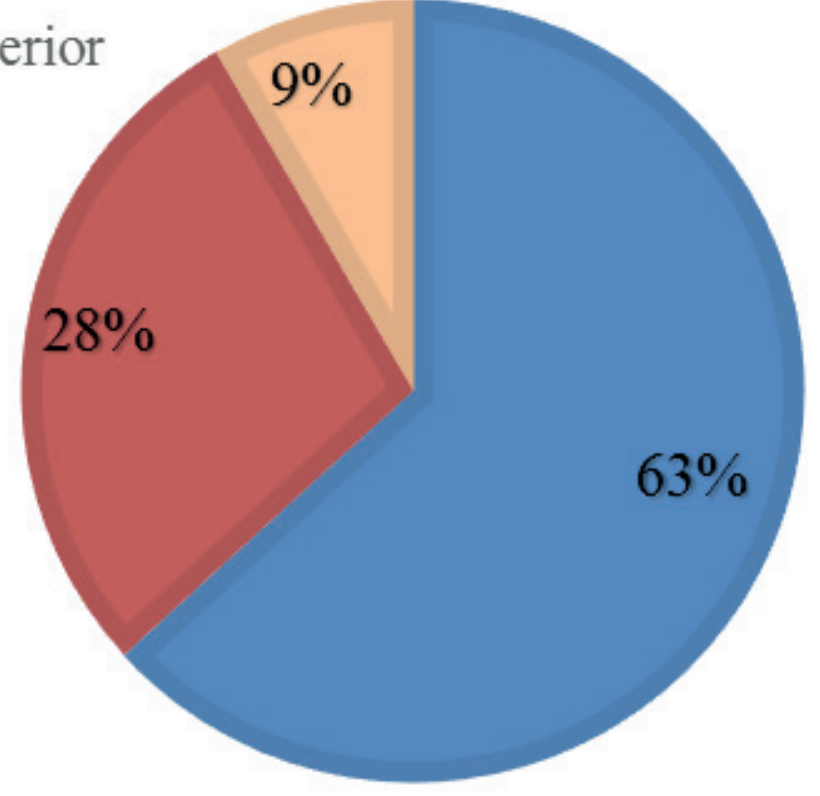
Considerando que até a década de 1970, realizar o doutorado em Geografia no Brasil só era possível na USP (Geografia Física e Geografia Humana), quase metade (46\%) dos docentes que obtiveram seu título de doutor em Geografia no Brasil, o fizeram nesta instituição. Na década de 1980 é aprovado o programa de doutorado da UNESP (Rio Claro) e no começo da década seguinte, são aprovados os cursos de doutorado na UFRJ e na UNESP (Presidente Prudente).

Somando os dois campus da UNESP (Rio Claro e Presidente Prudente), 26\% dos docentes obtiveram suas titulações nos programas de Geografia desta instituição. Somando-se os quase $8 \%$ da UFRJ, os cinco programas formaram quase $80 \%$ do total de docentes credenciados (figura 8).

Fig.8. IES de titulação dos docentes credenciados nos programas de pós-graduação em Geografia.

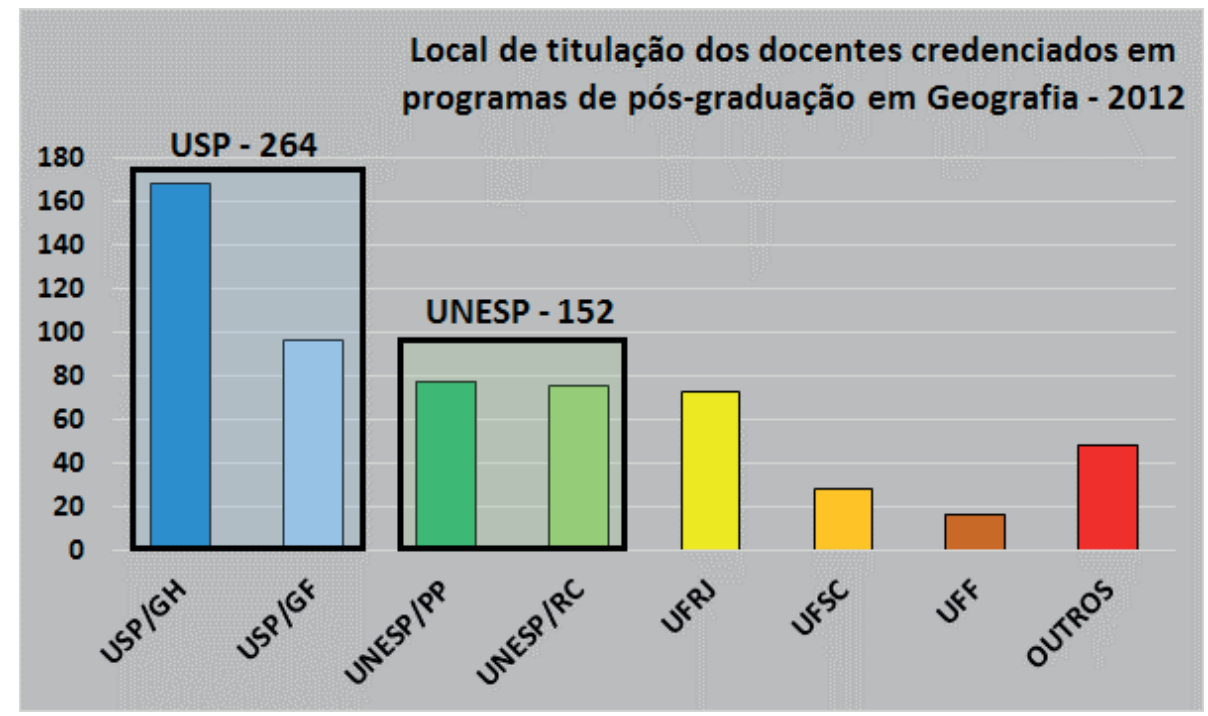

Com a instalação de outros 11 cursos de doutorado, entre 1999 e 2007 (UFSC, PUC/ MG, UFF, UNICAMP, UFS, UFMG, UFU, UFPE, UFRGS, UFPR e UFG), inicia-se um processo de desconcentração da formação de doutores pelo país. Estes programas já foram responsáveis por cerca de $10 \%$ da titulação dos docentes que atuam em programas de pós-graduação.

\section{Alunos Titulados}

Em 1998, titulavam-se anualmente no Brasil, cerca de 12 mil mestres e 4 mil doutores em todas as áreas do conhecimento. O que certamente indicavam números muito modestos para um país deste porte. Em 2012, titularam-se no Brasil cerca de 43 mil mestres e 14 
mil doutores. Trata-se, sem dúvida, de um enorme crescimento, mas, que não nos tirade uma situação de desconforto pela precariedade da proporção de pessoal titulado com relação aos demais grupos da população brasileira.

Estudos recentes do CGEE (Coordenação Geral de Assuntos Estratégicos) demonstraram que a renda média de um trabalhador de nível fundamental ou médio (sem curso superior) foi de cerca de $\mathrm{R} \$ 1.300,00$, em 2010. Com um diploma de nível superior, esta renda sobe $219 \%$, ou seja, passa para $\mathrm{R} \$ 4.100,00$.

Aqueles que possuem o título de doutor recebem, em média, cerca de R \$7.500,00, ou $85 \%$ de aumento da renda média mensal (figura 9).

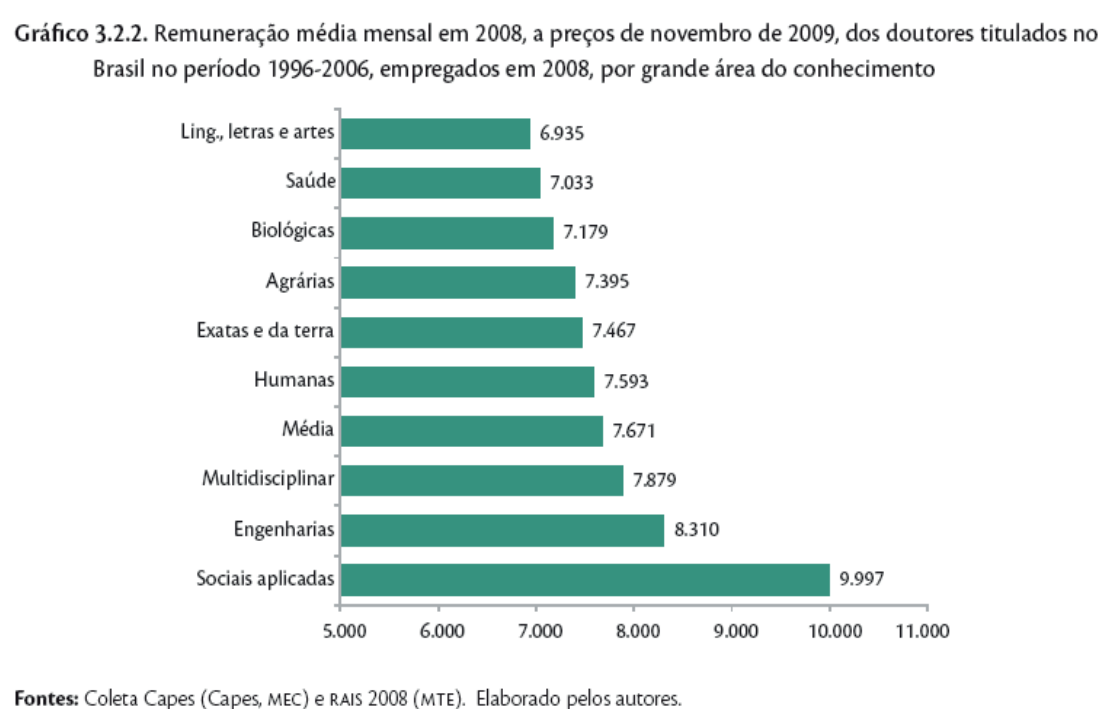

Estes dados demonstram o bônus educacional do capital humano que a pós-graduação proporciona. Observa-se que os doutores que se titularam na grande área das ciências Humanas, onde se encontra a Geografia, receberam salários médios de cerca de R\$ 7.600,00 mensais.É importante observar que nas ciências humanas, a maior parte dos alunos de mestrado e de doutoradoéproveniente das escolas públicas e de famílias de mais baixa renda. Assim, estes dados também indicam uma grande ascensão social e econômica, que podem ser consideradas como uma enorme inclusão social, por meio da educação.

No caso dos mestres e doutores na Geografia, o aumento da titulação foi ligeiramente maior do que a média nacional. Em 1998, formaram-se 120 mestres e 47 doutores. Em 2012, titularam-se 674 mestres e 258 doutores. Em ambos os casos, aumentou mais de 5 vezes o número de diplomados (figuras10 a e b). 
Fig.10a. Número de alunos matriculados e titulados no nível de mestrado - 1998 a 2012.

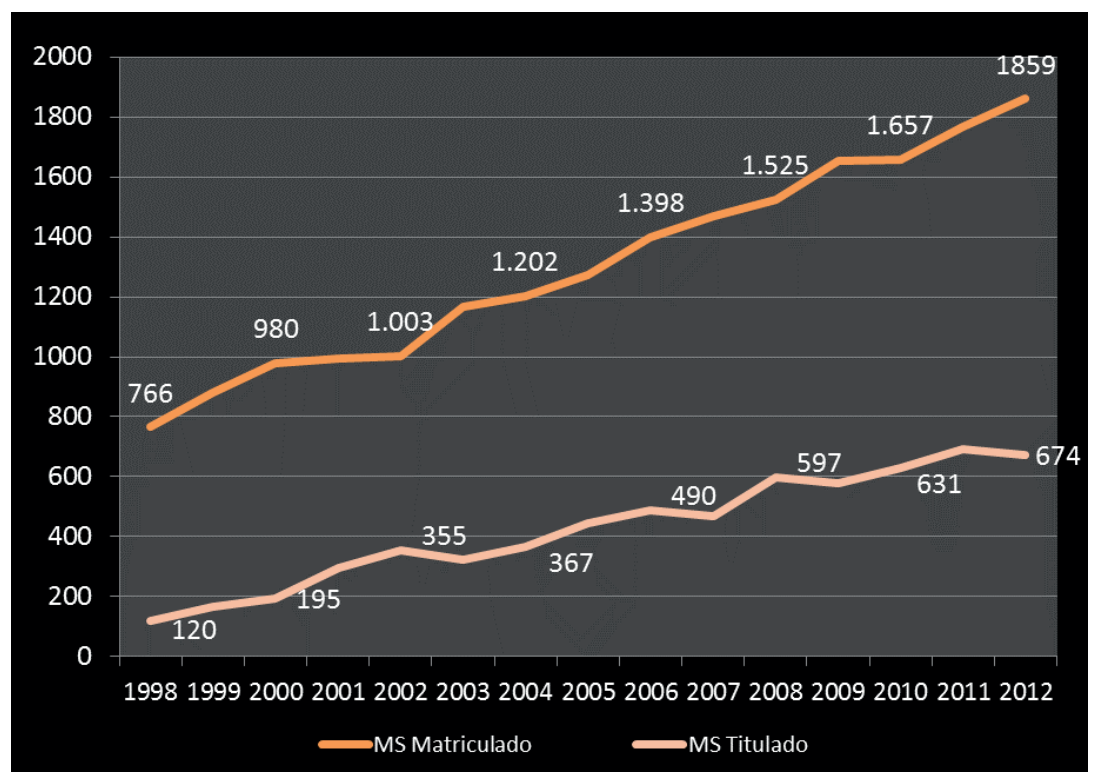

Fig.10b. Número de alunos matriculados e titulados no nível de doutorado - 1998 a 2012.

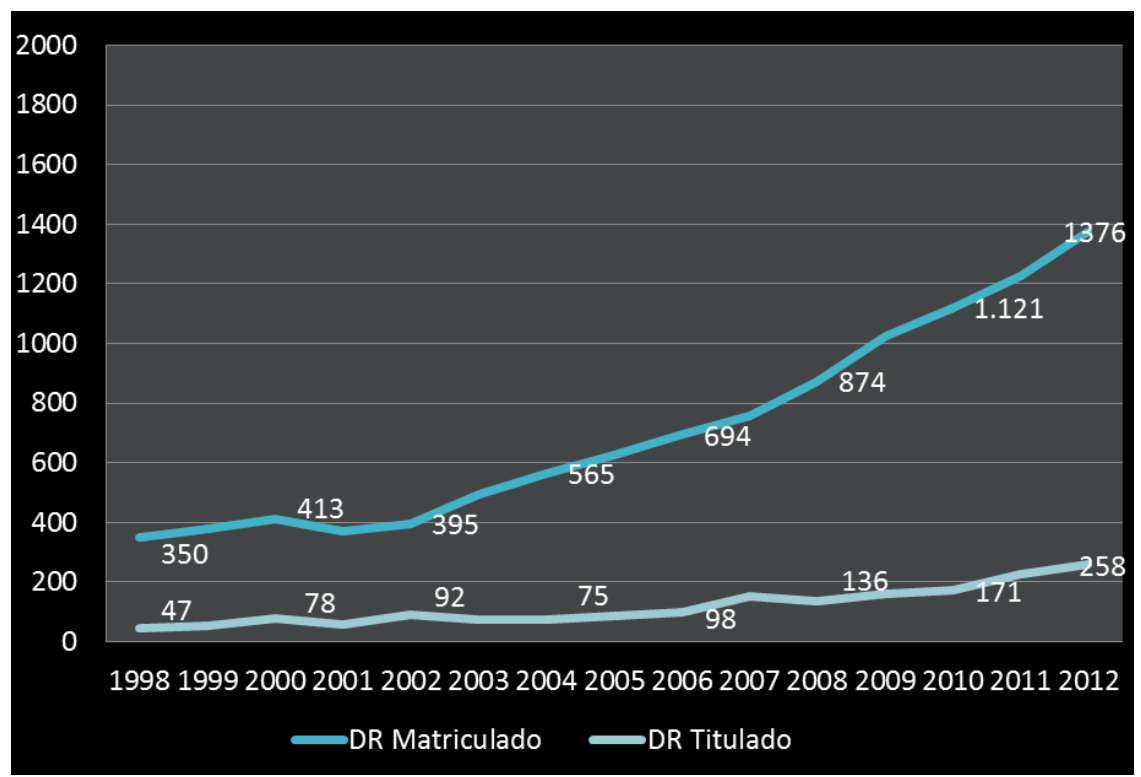

Neste mesmo período, o número de docentes permanentes credenciados nos programas de pós-graduação triplicou, passando de 330 para cerca de 760 docentes permanentes, o que resultou num aumento de trabalho de orientação docente, uma vez que em 1998 tínhamos cerca de 3,4 alunos matriculados por docente e, em 2012, esta proporção aumentou para mais de 4,3 alunos por docente. Nos 18 programas com doutorado consolidado, a média de orientação sobe para 5,5 alunos por docente. 
De certa forma, o rápido crescimento da área de Geografia, tanto no que se refere ao número de programas, o total de docentes credenciados e de alunos matriculados, reflete a vitalidade dos departamentos de Geografia espalhados pelas IES, notadamente da esfera pública (federais e estaduais) e das PUC's, que se qualificaram em termos da produção intelectual, para coordenarem programas de pós-graduação.

\section{A avaliação trienal de 2010/2012}

De forma contraditória, o princípio geral da avaliação que pretende medir a qualidade dos programas de pós-graduação definido pela Capes parte do pressuposto, que a avaliação é universal, e se pauta por critérios comuns a todas as áreas do conhecimento. Contraditória, pois, ao mesmo tempo que permite a instrumentalização dos itens avaliativos, gera estranhamentos das diversas culturas acadêmicas entre as ciências humanas e as ciências físicas e biológicas.

A natureza da produção do conhecimento pelos diversos campos do saber não é semelhante, assim como também diferem as temporalidades de sua duração e as formas de divulgação dos resultados de pesquisa ou de reflexão teórica.

Estas distâncias provocam incompreensões sobre os métodos e as práticas, fazendo com que, como se sabe, os critérios definidos pelas ciências físicas e biológicas se imponham para a avaliação das ciências humanas.

Em geral, as chamadas ciências "duras" dialogam internacionalmente, ao tratarem de fenômenos e problemas universais, por meio de uma linguagem matemática, que permite a validação dos resultados das pesquisas. Neste sentido, a produção de conhecimento exige o uso da língua inglesa e, a publicação internacional em periódicos reconhecidos por meio de indexadores e fatores de impacto.

Nas ciências humanas, o processo de reflexão exige um discurso seletivo, pautado em opções teóricas e na busca de referenciais que não necessariamente são definidos pela mesma racionalidade das ciências "duras". A natureza dos problemas estabelecidos para o desenvolvimento das pesquisas exige um diálogo, muitas vezes crítico e contraditório, em que mesmo permitindo um discurso universalizante, assume muitas vezes um caráter nacional/regional que o fundamenta e dá o seu sentido.

Em grande parte, a produção intelectual derivada desta forma de se produzir conhecimento, concretiza-se na forma de livros e coletâneas. 
À despeito destes problemas que tendem a uniformizar a avaliação, é inegável o aprimoramento dos critérios adotados pelo CTC da Capes desde 2001. A cada triênio, os quesitos e os itens são discutidos e os parâmetros aperfeiçoados. À partir de 2010, as reuniões do CTC, por determinação da Diretoria de Avaliação da Capes, passou a ser realizada com a presença de todos os coordenadores de área. Tal fato propiciou um debate mais democrático sobre as especificidades das diferentes áreas do conhecimento, que resultou em flexibilização de itens e quesitos, de acordo com as demandas das áreas.

Neste contexto, a área de Geografia pode particularizar uma série de importantes instrumentos de avaliação, que foram discutidos com os coordenadores dos programas em duas reuniões em Brasília, no sentido de adequar as demandas da área.

Entre as principais modificações realizadas, com o propósito de investir numa avaliação mais qualitativa, introduzimos a avaliação dos cinco principais produtos intelectuais de cada docente, reclassificamos os periódicos acrescentando um critério de avaliação pela comunidade, valorizamos e equilibramos a importância da produção por meio de livros e capítulos na divulgação dos resultados de pesquisa, diminuímos o peso e a importância do tempo médio de titulação das dissertações e teses, incluímos um item para valorizar outras atividades realizadas pelos alunos, como complemento a sua formação diferenciada e mais plural e, minimizamos os itens quantitativos, em prol dos qualitativos.

\section{Critérios da avaliação}

Passados 15 anos (5 períodos de avaliações trienais), os princípios e os critérios gerais já estão suficientemente internalizados pela comunidade e pelos programas de pós-graduação. A Área de Geografia sempre se posicionou de forma crítica e incisiva nos debates junto ao CTC/Capes, defendendo princípios qualitativos e resistindo à tendência de homogeneização de critérios que são estranhos às práticas das ciências humanas.

No triênio 2010/2012, estabeleceram-se canais de diálogo com a comunidade e, principalmente com os coordenadores dos programas no sentido de rediscutir os critérios, índices e proporções dos itens de avaliação, com o objetivo de aperfeiçoa-lo, atendendo às demandas da área. Esta tarefa é uma luta constante, que envolve a sensibilidade em ouvir a comunidade, interpretar as críticas, construir argumentos e defende-los junto ao CTC/Capes.

Como resultado das reuniões com os coordenadores e das mediações junto à Capes, definiu-se para a avaliação trienal, no que se refere à métrica da ficha de avaliação, a proporção de 15\% para o Corpo Docente, 35\% para o Corpo Discente, 35\% para a Produção Intelectual e 15\% para a Inserção Social, mantendo-se a mesma ponderação do triênio 2007/2009. Porém, com várias modificações da pontuação dos itens internos aos quesitos. 
Os princípios norteadores da avaliação, com relação à Proposta do Programa, consistem na apresentação de um projeto coerente, em que a área de concentração, as linhas de pesquisa, os projetos dos docentes, as disciplinas curriculares e as dissertações e teses defendidas, constituam de forma articulada uma proposta acadêmica consistente.

Dois importantes itens deste quesito foram valorizados (ainda que muitos programas não atentem para a relevância destes aspectos)e, se referem: a) ao plano de metas (planejamento das atividades), com vistas ao seu melhor desempenho; $b$ ) instrumentos de auto avaliação, e de seminários de avaliação, com a participação dos docentes e discentes do programa.

É consenso que todos os docentes do corpo permanente do programa sejam responsáveis por projeto de pesquisa, por disciplina regular ministrada pelo menos 1 vez no triênio, orientem alunos e apresentem produção intelectual compatível com o nível do programa. Valorizou-seatividades de intercâmbio e realização de estágios e pós-doutorado em IES nacionais e do exterior com elevada qualificação na área de atuação do docente.

Outra mudança empreendida neste triênio, com relação ao corpo, referiu-se a considerar as atividades acadêmicas realizadas em outras Instituições de Ensino Superior IES (Procad, estágios em laboratórios e intercâmbio institucional) e instituições públicas e privadas de reconhecida qualidade na área, como forma de diversificação da formação dos mestrandos e doutorandos. No caso de alunos de doutorado valorizou-se a realização de estágios no exterior, em grupos consolidados de instituições relevantes. Considerou-se a realização de estágio de docência (mesmo para os alunos não bolsistas) e a participação em eventos científicos.

As principais modificações da ficha de avaliação deste triênio 2010/2012, entretanto, referiram-se ao quesito "Produção Intelectual", que tem sido alvo de muitas críticas da comunidade acadêmica, por ainda mensurar mais as suas quantidades do que a qualidade. Como uma tentativa de reverter este quadro e valorizar a produção de qualidade, neste triênio a produção intelectual foi avaliada de duas formas:

a. A primeira, por meio dos mesmos critérios da Avaliação Trienal 2010, ou seja, os produtos publicados pelo corpo docente permanente do programa, incluindo os Periódicos, Livros (e capítulos), artigos em anais de eventos e produção técnica, na proporção da média da área (no triênio anterior, a proporção foi $85 \%$ para periódicos, livros e capítulos; $10 \%$ para artigos em anais de eventos e 5\% para a produção técnica).

b. A segunda, considerando a avaliação da produção qualificada indicada pelos docentes permanentes do programa, no total de 5 (cinco) produtosno triênio 2010/2012. 
Destes, pelo menos 3 (três) bibliográficos (artigos em periódicos, livros e capítulos de livros). Os outros 2 (dois), quaisquer produtos que atestem ou indiquem qualidade, relevância e importância para o Sistema Nacional de Pós-Graduação (SNPG) como:

- Artigo em anais de eventos científicos de alto nível;

- Produção técnica de qualidade (relatórios, cartas, mapas, softwares, protocolos, patentes, documentos, etc.);

- Participação em comissões/equipes de trabalho de alto nível, incluindo representação em entidades científicas;

- Elaboração de material didático de forte impacto;

- Prestação de serviços a órgãos públicos e/ou privados de grande relevância e impacto social, educacional, cultural, econômico;

- Participação como docente convidado em atividades de elevada distinção (docente convidado em universidades e/ou outras instituições nacionais ou estrangeiras);

- Premiação de alto nível; etc.

Essa alteração nos princípios de avaliação da produção intelectual demonstra a preocupação da Área de Geografia em indicar para a comunidade, a valorização da qualidade do que se tem produzido e realizado de relevante, e não apenas da quantidade.

Considera-se que não publicar é sempre ruim, mas publicar muito, não é necessariamente bom. Avaliou-se como adequado que os docentes permanentes pertencentes aos programas de pós-graduação, que orientam alunos, ministram disciplinas e que coordenam projetos de pesquisa, publiquem $\mathbf{1}$ (um) produto qualificado por ano ou 3 (três) produtos no triênio, conforme indicado pela média atual da área. Desta forma, independente da quantidade de produtos publicados pelos docentes, o que realmente importa é o impacto desta produção no sistema de pós-graduação e na produção intelectual da área para a sociedade. A somatória de produtos menores não pode suplantar a produção de qualidade.

Entretanto, como esta mudança foi proposta no meio do triênio, considerou-se mais acertado e justo, propor um sistema híbrido, em que parte do que foi realizado no triênio passado se mantenha, incorporando as novidades.

Com esta métrica, rompeu-se com o princípio anterior que privilegiava a produção crescente que provocava uma necessidade de se produzir cada vez mais em cada triênio. Estabeleceu-se um padrão considerado como adequado e sustentado pela média históri- 
ca da área, de 1 produto intelectual (periódico/livro/capítulo), 3 artigos em anais de eventos científicos e, 6 produtos técnicos (pareceres, palestras, apresentação de trabalho, etc.) por ano. Assim, estabelecemos a seguinte métrica (figura 11):

Fig.11. Pontuação dos produtos intelectuais por classe qualitativa. (Obs: a pontuação se refere à somatória dos três tipos de produção, ponderada pelo peso de cada uma no período de 3 anos).

\begin{tabular}{|c|c|c|c|c|c|c|c|c|}
\multirow{2}{*}{ MENÇÃO } & \multicolumn{4}{|c|}{ PERIÓdICO+LIVRO (85\%) } & \multicolumn{3}{c|}{ ANAIS (10\%) } & \multicolumn{2}{|c|}{$\begin{array}{c}\text { PROD. TÉCNICA } \\
\text { (5\%) }\end{array}$} & \multirow{2}{*}{ TOTAL } \\
\cline { 2 - 9 } & Quant. & Estrato & Pontos & Quant. & Pontos & Quant. & Pontos & \\
\hline MB & 3 & $\mathrm{~A} 1 / \mathrm{B} 1-\mathrm{L} 3 / \mathrm{L} 4$ & 210 & 9 & 90 & 18 & 90 & 180 \\
\hline $\mathrm{B}$ & 3 & $\mathrm{~A} 1 / \mathrm{B} 2-\mathrm{L} 2 / \mathrm{L} 4$ & 150 & 6 & 60 & 12 & 60 & 135 \\
\hline $\mathrm{R}$ & 2 & $\mathrm{~A} 1 / \mathrm{B} 2-\mathrm{L} 2 / \mathrm{L} 4$ & 100 & 4,5 & 45 & 9 & 45 & 90 \\
\hline $\mathrm{F}$ & 1 & $\mathrm{~A} 1 / \mathrm{B} 2-\mathrm{L} 2 / \mathrm{L} 4$ & 50 & 3 & 30 & 6 & 30 & 45 \\
\hline $\mathrm{D}$ & $<1$ & $\mathrm{~A} 1 / \mathrm{B} 2-\mathrm{L} 2 / \mathrm{L} 4$ & $<50$ & $<3$ & $<30$ & $<6$ & $<30$ & $<45$ \\
\hline
\end{tabular}

Quanto ao quesito de inserção social, a área considerou fundamental que o programa apresente informações sobre sua atuação nos diversos setores da sociedade, em níveis locais, regionais, nacionais e internacionais demonstrando como se dá a sua participação na construção de um país mais justo, no combate às desigualdades sociais, aos preconceitos de todo tipo, na formação de recursos humanos voltados para a qualificação profissional e como contribuição à ciência, à tecnologia e à inovação.

Valorizou-se a qualidade e o nível das informações sobre o programa, por meio de página em sítio da internet contendo todas as informações, incluindo as dissertações e teses defendidas, critérios de seleção de novos alunos, situação dos egressos e critérios para a utilização dos recursos financeiros, de modo a demonstrar transparência pública.

\section{Qualis periódicos}

Um dos maiores desafios da avaliação é mensurar a qualidade da produção intelectual publicada por meio de periódicos e livros. As ciências humanas tem a tradição de divulgar grande parte de sua produção por meio de livros (autorais ou coletâneas). Entretanto, a Geografia apresenta uma particularidade que é a de que a produção varia entre a Geografia Física e a Geografia Humana. Enquanto a primeira utiliza os periódicos com mais frequência, esta última concentra em publicações na forma de livros. Assim, foi necessário criar uma métrica que equivalesse estas duas formas de produção. 
Do total de 1425 periódicos classificados pela Área de Geografia (Qualis 2012), apenas $21,8 \%$ apresentava algum tipo de indexação que permitisse a obtenção de índices de impacto e, mesmo assim, são basicamente os periódicos internacionais e das áreas temáticas vinculadas às Geociências e às Ciências Ambientais.

Outra característica refere-se ao fato de que a maioria dos periódicos listados no Qualis/Geografia classifica-se em outros ramos da ciência, ou seja, dos 1425 periódicos do Qualis/Geografia, apenas 206 (14\%) são efetivamente revistas da área.

Entendeu-se por revista da área de Geografia, todo e qualquer periódico cuja editoria ou grande parte do conselho editorial seja formada por pesquisadores de temas próprios da Geografia e, que em sua maioria, os autores dos artigos publicados estejam vinculados à área.

Pela natureza interdisciplinar e pela interlocução da Geografia com outras áreas de conhecimento, a comunidade tem publicado em centenas de periódicos de outros ramos da ciência, alguns tradicionalmente mais afins, como as Ciências Humanas (História, Filosofia) as Ciências Sociais, as Geociências. Mas, também temos publicado em periódicos de áreas menos óbvias, como na Química, Medicina, Literatura e Ciências Exatas (figura 12).

Fig. 12. Distribuição dos periódicos do Qualis de Geografia por área de conhecimento. ${ }^{12}$

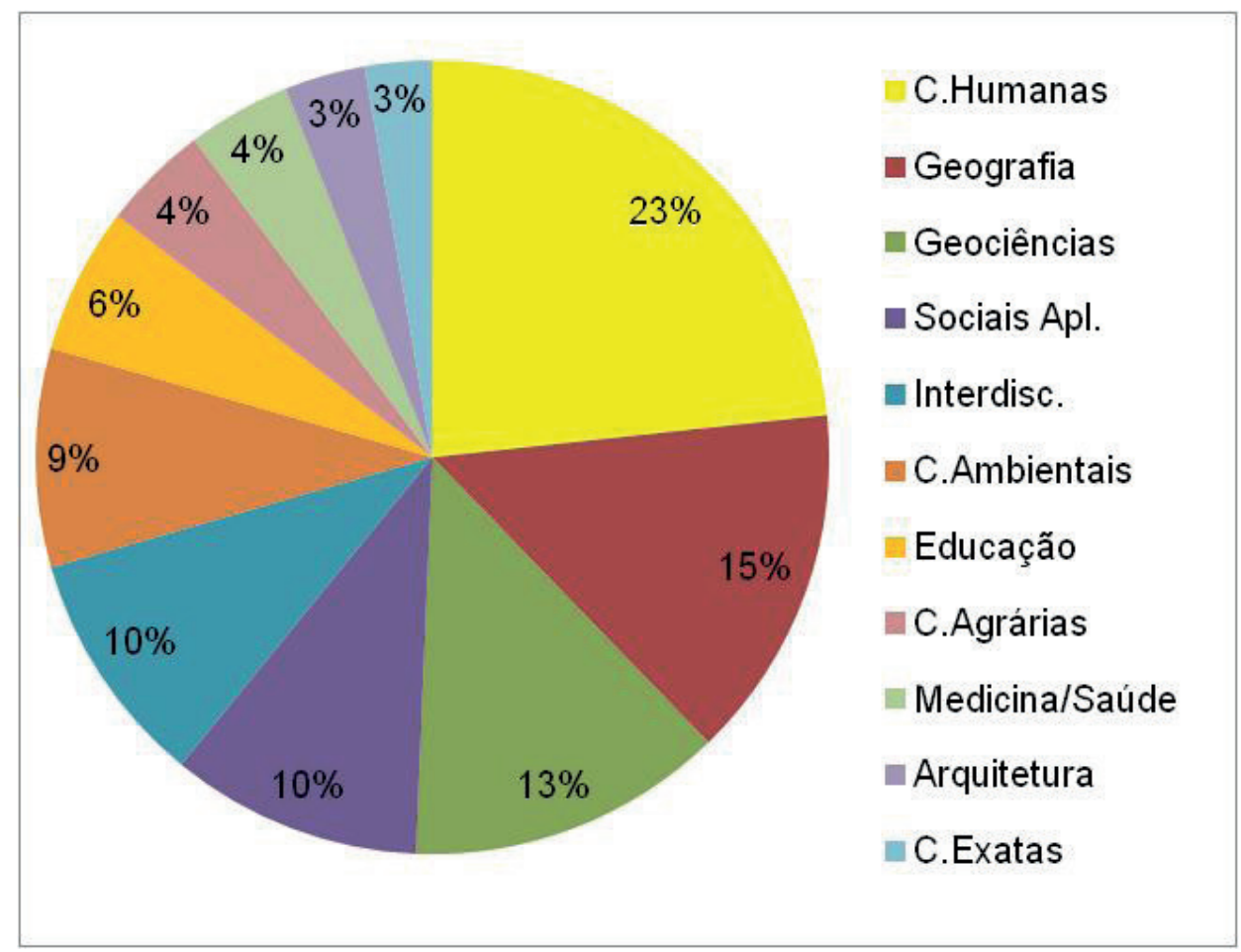

${ }_{12}$ Obs. As áreas de conhecimento classificadas neste gráfico foram consideradas por critérios temáticos. Ou seja, o que define um periódico ser de uma área e não de outra é o conjunto de temas próprios de cada área de conhecimento. Assim, um periódico classificado como sendo da Área de História é um periódico que publica temas próprios da área e, cuja maioria dos autores são pesquisadores da área. 
No que se refere à classificação dos periódicos (qualis) é importante destacar que a Geografia apresenta um conjunto de características, típicas das ciências humanas e sociais, em que a grande maioria dos periódicos da área não está indexada em bases internacionais. Isto significa que não temos a possibilidade de classificá-los por seu fator de impacto, aos moldes das demais áreas de conhecimento.

Vários desafios tiveram que ser enfrentados para esta tarefa, considerando as características dos periódicos, a importância que a comunidade atribui a estes veículos e, a qualidade de seu conteúdo.

Primeiramente foram elaboradas duas listas de periódicos. A primeira, com os periódicos nacionais e estrangeiros classificados como veículos de conteúdo geográfico. A segunda lista, com os demais, cujos conteúdos se referem predominantemente a outras áreas do conhecimento. Estes fatos demonstram uma importante característica da Geografia, que se refere a uma produção intelectual pulverizada em enorme gama de periódicos.

Assim, a área classificou os periódicos por meio de dois conjuntos de critérios:

1. Os 1219 periódicos considerados como de outras áreas (que não publicam majoritariamente artigos de temas próprios da Geografia), foram avaliados por meio dos conceitos atribuídos pelas demais áreas, observando o grau de interesse da Geografia.

A classificação obedeceu os seguintes critérios de impacto:

- A1 - fator de impacto acima de 1,5 (JCR);

- A2 - fator de impacto de 0,5 a 1,49;

- B1 - fator de impacto de 0,01 a 0,49;

- B2 a B5 -utilização dos Qualis de cada área do conhecimento para avaliar os periódicos relacionados às suas temáticas.

2. Os 206 periódicos considerados como pertencentes à Área de Geografia foram avaliados considerando 3 critérios: fator de impacto; ficha de avaliação; e, consulta de avaliação pela comunidade:

- 2.a. Índice $\mathrm{H}$ - fator de impacto do periódico, em que se calcula a quantidade de citações de artigos, por unidade de tempo. Foi calculado o IH considerando o período de 2003 a 2012 (10 anos). Os valores variaram entre 0 e 15.

Foi considerado, também o Índice G - fator de concentração de artigos de impacto num periódico, em que se calcula a quantidade de artigos mais citados, por unidade 
de tempo. Os valores variaram entre 0 e 28. Citações - número total de citações de artigos por periódico. Os valores variaram entre 0 e 970 . Estes indicadores foram obtidos por meio do $\mathrm{POP}^{13}$ e Google Acadêmico (figura 13).

Fig.13. Métrica para cálculo do índice $h$.

\begin{tabular}{|c|c|c|c|c|c|}
\hline \multicolumn{2}{|c|}{ Índice H } & \multicolumn{2}{|c|}{ Índice G } & \multicolumn{2}{|c|}{ Citações } \\
\hline $\mathrm{A} 1$ & 12 a 15 & $\mathrm{~A} 1$ & mais de 20 & A1 & mais de 500 \\
\hline $\mathrm{A} 2$ & 8 a 11 & $A 2$ & 11 a 20 & A2 & 201 a 500 \\
\hline B1 & 4 a 7 & B1 & 5 a 10 & B1 & 71 a 200 \\
\hline B2 & 3 & B2 & 3 a 4 & B2 & 16 a 70 \\
\hline B3 & 2 & B3 & 2 & B3 & 8 a 15 \\
\hline B4 & 1 & B4 & 1 & B4 & 1 a 7 \\
\hline B5 & 0 & B5 & 0 & B5 & 0 \\
\hline
\end{tabular}

- 2.b. Ficha de Avaliação ${ }^{14}$ - A ficha de avaliação do periódico consiste na verificação de 5 quesitos considerados fundamentais, de acordo com a discussão realizada há 4 triênios (com pequenas modificações), pelas áreas das humanidades. Os quesitos são:

- Normalização

- Publicação

- Circulação (indexadores)

- Autoria e Conteúdo

- Gestão Editorial
14 pontos

13 pontos

10 pontos

42 pontos

21 pontos

- 2.c. Consulta à comunidade - A consulta à comunidade foi realizada por meio de uma ficha contendo 3 itens de avaliação, por meio de software elaborado especificamente para esta finalidade, contendo: 1) Grau de conhecimento do periódico (incluindo o status - editor, membro do conselho editorial, parecerista ou leitor.); 2) Contribuição científica do periódico para a produção do conhecimento na pós-graduação; 3) Nível de seletividade exigida para publicar no periódico (Figura 14).

\footnotetext{
${ }^{13}$ POP é um software gratuito que contabiliza a produção intelectual e todas as citações efetuadas em dado período de tempo. Para maiores informações consulte www.harzing.com.

${ }^{14}$ A ficha de avaliação dos periódicos está disponível em: www.capes.gov.br/component/content/article/44-avaliacao/4673-geografia
} 
Fig. 14. Modelo utilizado para a consulta à comunidade sobre os periódicos da área.

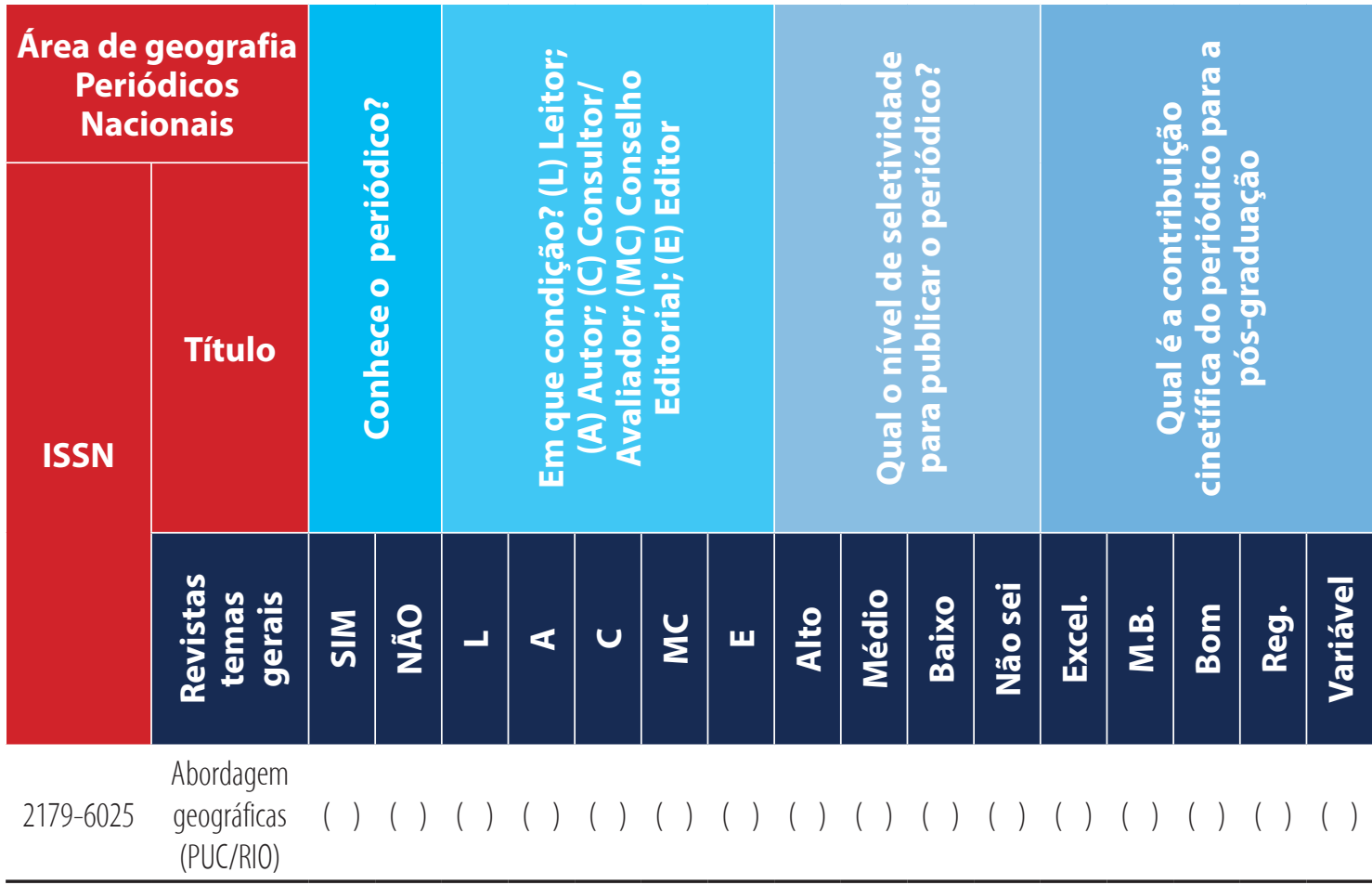

Todos os docentes credenciados como permanentes nos programas de pós-graduação em Geografia tiveram a oportunidade de avaliar os periódicos (723 docentes). Obtivemos 465 respostas, sendo 378 online e 87 fichas enviadas por e-mail, totalizando $64,6 \%$ do universo de possíveis avaliadores. Com $2 / 3$ dos docentes avaliando os periódicos, consideramos a pesquisa como representativa da comunidade. A métrica final para obtenção da pontuação, neste critério foi (figura 15):

Fig. 15. Métrica dos itens da consulta à comunidade. ${ }^{15}$

\begin{tabular}{|c|c|c|c|c|c|c|c|}
\hline \multicolumn{2}{|c|}{ Conhece o periódico } & \multicolumn{3}{|c|}{ Qualidade do periódico } & \multicolumn{3}{|c|}{ Seletividade do periódico } \\
\hline Nota & Critério & Nota & Excel & Excel/MB & Nota & Alto & Alto/Med \\
\hline A1 & mais de $70 \%$ & A1 & $+40 \%$ & $+80 \%$ & A1 & $+50 \%$ & \\
\hline A2 & $55 \%$ a $70 \%$ & A2 & $+30 \%$ & $+70 \%$ & $\mathrm{~A} 2$ & $+40 \%$ & \\
\hline B1 & $40 \%$ a $55 \%$ & B1 & $+20 \%$ & $+60 \%$ & B1 & $+30 \%$ & \\
\hline B2 & $30 \%$ a $40 \%$ & B2 & $+20 \%$ & $+50 \%$ & B2 & $+25 \%$ & $+70 \%$ \\
\hline B3 & $20 \%$ a $30 \%$ & B3 & $+15 \%$ & $+40 \%$ & B3 & $+20 \%$ & $+60 \%$ \\
\hline B4 & $10 \%$ a $20 \%$ & B4 & $+10 \%$ & $+30 \%$ & B4 & $+15 \%$ & $+50 \%$ \\
\hline B5 & até 10\% & B5 & até 10\% & até 30\% & B5 & até 15\% & até 50\% \\
\hline & & & penas & eles qu & hece & seriódic & \\
\hline
\end{tabular}

15 É importante ressaltar que para a obtenção da classificação dos critérios sobre a qualidade e a seletividade dos periódicos foi necessária a adoção de uma pontuação combinada entre o excelente e o muito bom, no primeiro caso e, alto e médio no segundo. 
A avaliação final foi obtida pela combinação da análise qualitativa dos 3 itens, como o demonstrado no exemplo a seguir (figura 16):

Fig.16. Modelo da avaliação final dos periódicos da área de Geografia.16

\begin{tabular}{|c|c|c|c|c|c|c|c|c|c|c|c|}
\hline \multirow[b]{2}{*}{ Título } & \multirow{2}{*}{$\begin{array}{c}\text { ÍNDICE } \\
h\end{array}$} & \multirow{2}{*}{$\begin{array}{c}\text { ÍNDICE } \\
\text { G }\end{array}$} & \multirow[b]{2}{*}{$a^{5 p^{60}}$} & \multirow{2}{*}{$\begin{array}{c}\text { FINAL } \\
\text { ÍNDICE } \\
\end{array}$} & \multirow{2}{*}{ FICHA } & \multirow{2}{*}{$\begin{array}{l}\text { FICHA } \\
\text { FINAL }\end{array}$} & \multicolumn{3}{|c|}{ CONSULTAA COMUNIDADE } & \multirow{2}{*}{$\begin{array}{c}\text { CONSULTA À } \\
\text { COMUNIDADE } \\
\text { FINAL }\end{array}$} & \multirow{2}{*}{$\begin{array}{l}\text { QUALIS } \\
\text { TRIÊNIO } \\
\text { FINAL }\end{array}$} \\
\hline & & & & & & & \begin{tabular}{|c|} 
conhece o \\
periódico ?
\end{tabular} & \begin{tabular}{|c|} 
qualidade do \\
periódico
\end{tabular} & \begin{tabular}{|l|} 
seletividade \\
do periódico
\end{tabular} & & \\
\hline REVISTAS GEOGRAFIA & 0 a 15 & 0 a 30 & 0 a 970 & A1 a B5 & 0 a 100 & A1 a B5 & 0 a 100 & 0 a 100 & 0 a 100 & A1 a B5 & FINAL \\
\hline Revista Brasileira de Geomorfologia (UGB) & A1 & A2 & $\mathrm{A} 1$ & A1 & 85 & A1 & B1 & A1 & A1 & A2 & A1 \\
\hline Boletim Goiano de Geografia (UFG/Goiânia) & A2 & A2 & A2 & A2 & 77 & A2 & B1 & B2 & B2 & B2 & A2 \\
\hline Cidades (GEU - Grupo de Estudos Urbanos) & A1 & $\mathrm{A} 1$ & A1 & A1 & 77 & A2 & B1 & A1 & A1 & A2 & A2 \\
\hline Geosul (UFSC/Florianópolis) & A2 & A2 & A1 & A2 & 52 & B2 & A1 & B1 & A2 & A2 & A2 \\
\hline Geousp (USP/São Paulo) & A2 & A2 & A2 & A2 & 54 & B2 & A1 & $\mathrm{A} 1$ & $\mathrm{~A} 1$ & A1 & A2 \\
\hline RA'E GA (UFPR/Curitiba) & A2 & A1 & $\mathrm{A} 1$ & A1 & 71 & A2 & B1 & B2 & B1 & B1 & A2 \\
\hline Revista da ANPEGE (ANPEGE) & B1 & B1 & B1 & B1 & 72 & A2 & A1 & A2 & A1 & A1 & A2 \\
\hline Sociedade \& Natureza (UFU/Uberlândia) & A2 & B1 & A2 & A2 & 83 & A1 & A2 & A2 & A2 & A2 & A2 \\
\hline Terra Livre (AGB) & A2 & A2 & A2 & A2 & 58 & B2 & A1 & A1 & A1 & A1 & A2 \\
\hline
\end{tabular}

Como resultado da classificação dos periódicos, por meio dos critérios adotados, pode-se considerar cerca de 40\% das revistas da área de Geografia como de qualidade - A1, A2 e B1 (figura 17). Do total dos mais de 1400 periódicos avaliados, 1/3 deste universo também foi classificado como veículos qualificados. Isto significa que 86 revistas da Geografia e 382 periódicos de áreas afins estiveram à disposição dos docentes e discentes da pós-graduação para publicar seus resultados de pesquisa.

A despeito de todas as críticas e mesmo considerando as limitações que o sistema Qualis ainda apresenta, é inegável o papel indutor da avaliação, como agente influenciador de melhoria da seletividade dos periódicos, do respeito à periodicidade, da qualidade gráfica e da divulgação por meio de sistemas online.

Fig. 17. Estratos do Qualis da Área de Geografia no triênio 2010-2012.

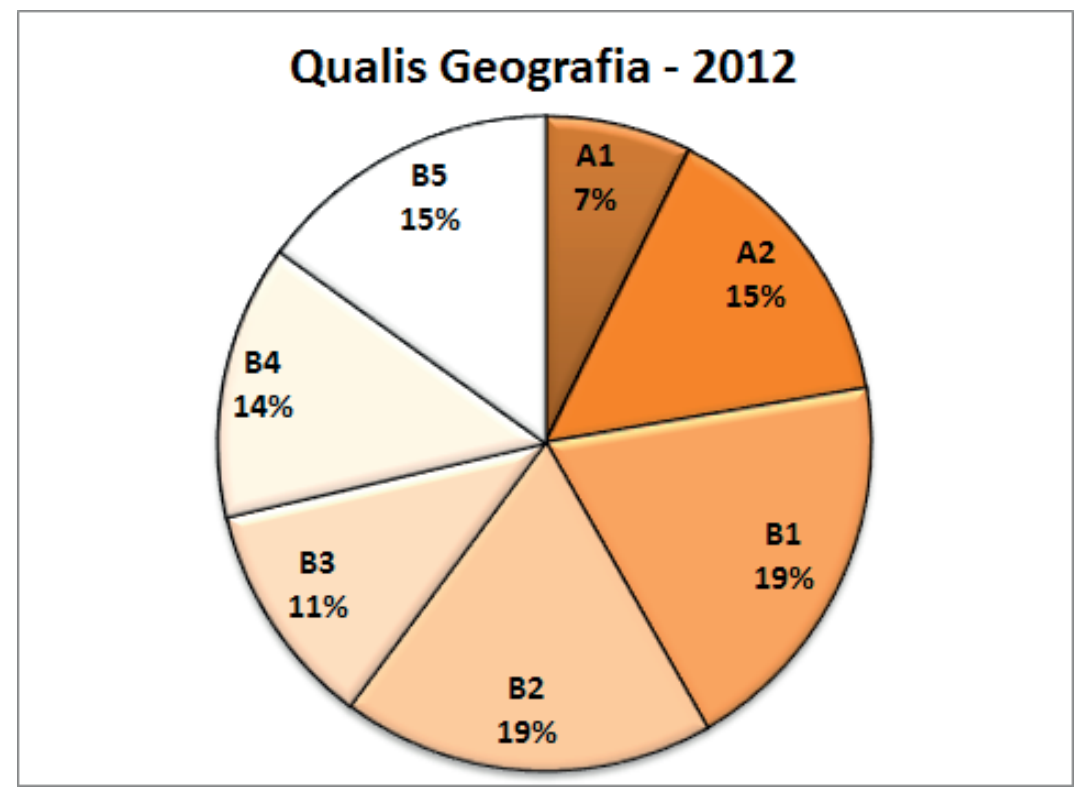

${ }^{16}$ A pontuação final foi a média ponderada entre os três critérios. 


\section{Classificação de livros}

No triênio 2010/2012, cerca de 35\% dos produtos bibliográficos dos docentes permanentes foram no formato de livros e capítulos de livros.A dificuldade de se avaliar este tipo de produção é que, ao contrário dos artigos em periódicos, em que a avaliação é realizada para classificar o periódico em geral e não o artigo em particular, no caso dos livros, é ele, em si que é avaliado individualmente, na falta de tradição de editoras acadêmicas, universitárias que seriam passíveis de serem avaliadas em função de seu conselho editorial, catálogo de qualidade com temas na área de avaliação, entre outros.

Assim, mesmo diante destas dificuldades, a Área de Geografia tem aprimorado os critérios de classificaçãodo conjunto dos livros produzidos, desde 2001, em função da importância para este tipo de produção representa. Além disto, no entendimento do CTC/ Capes, se os livros são um importante instrumento de divulgação da pesquisa, estes precisam ter critérios de avaliação de sua qualidade.É relevante lembrar que a classificação das obras publicadas é realizada no contexto da pós-graduação.

Neste sentido, a Área de Geografia entende que:

3. Definição de Livro:Compreende-se por livro um produto impresso ou eletrônico que possua ISBN ou ISSN (para obras seriadas) contendo no mínimo 50 páginas, publicado por editora pública ou privada, associação científica e/ou cultural, instituição de pesquisa ou órgão oficial, tanto em formato impresso, quanto digital.

4. Critérios de seleção para qualificação:A avaliação de livros é aplicada exclusivamente para classificação da produção intelectual que resulte de investigação nas suas diferentes modalidades. Para efeito desse roteiro são consideradas: obras integrais, coletâneas, dicionários, atlas, mapas ou enciclopédias, anais (texto completo) desde que seu conteúdo traduza a natureza científica da produção.

5. Instrumento de Avaliação:

- Parte I: Dados de Identificação da Obra - elegíveis para qualificação, segundo critérios adotados pela área.A identificação da obra contém: título da obra; autor(es) e ou organizador(es); ISBN; editora; local da edição; número de páginas; ano da primeira edição; número e ano da edição enviada; tiragem; formato (impresso ou eletrônico); número de capítulos da coletânea.

- Parte II: Avaliação pela Comissão de classificação de Livros - A avaliação dos livros é realizada com o exemplar do produto a ser qualificado para que o exame, pela Comissão, de suas características formais e de conteúdo possa permitir o 
correto preenchimento das informações. A avaliação contempla as características particulares da Área de modo a observar os dados mínimos para classificação do produto como livro, os aspectos formais da obra e o tipo e natureza do texto.

- Aspectos formais: Compreende características de autoria, editoria bem como informações adicionais sobre fontes de financiamento, reedição, prêmios, etc. Considera-se obra integralautoria única ou até dois autores e livro em co-autoria ou coletâneacom mais de dois autores. Tipo e natureza do texto: Considerada a natureza científica, esse requisito prevê seu detalhamento bem como o tipo de obra avaliada (obra integral, coletânea, dicionário, atlas, mapa, enciclopédia, etc.).

- Parte III: Avaliação do conteúdo da obra - A avaliação de conteúdo baseia-se em três quesitos: relevância temática, caráter inovador da contribuição e potencial de impacto.Relevância: contribuição para o desenvolvimento científico e tecnológico da área de conhecimento; contribuição para a resolução de problemas nacionais relevantes; atualidade da temática; clareza e objetividade do conteúdo no que se refere à proposição, exposição, desenvolvimento dos temas tratados; rigor científico; senso crítico no exame do material estudado; bibliografia que denote amplo domínio de conhecimento; qualidade e adequação das representações cartográficas e iconográficas, linguagem e estilo.Inovação: originalidade na formulação do problema de investigação; caráter inovador da abordagem ou dos métodos adotados; contribuição inovadora para o campo do conhecimento ou para aplicações técnicas. Potencialidade do impacto:circulação e distribuição; reimpressão ou reedição; língua; possíveis usos no âmbito acadêmico e fora dele.

\section{Classificação dos estratos}

A classificação dos livros nos níveis L1 a L4 é estabelecida pela pontuação atribuída pela Área aos aspectos formais, tipo e natureza da obra e avaliação de conteúdo.Pontuação: L4 = 100; L3 = 75; L2 = 50; L1 = 25 .

Além dos quatros estratos que foram utilizados para estabelecer pontos na avaliação da produção intelectual dos programas, há um estrato - sem pontuação - para aquelas obras consideradas não classificáveis pela comissão de avaliação (LNC), por não atenderem aos critérios anteriormente citados.

Nos estratos superiores da classificação - L3 e L 4, encontram-se as obras de maior relevância para o desenvolvimento científico da área e para a formação de mestres e doutores. 
Convém observar, uma vez mais, que os capítulos são considerados tendo por unidade de referência o livro no qual foram publicados. A soma de capítulos na mesma coletânea não pode ultrapassar a pontuação de uma obra integral para fins de avaliação da produção do programa, caso contrário, gera enormes distorções na pontuação.

No triênio 2010/2012 foram publicadas 1286 obras por docentes e discentes da Área de Geografia (cerca de 40\% a mais do que no triênio anterior). Destas, 218 obras não foram classificadas, ou por não se tratar de livro, ou por não terem sido enviadas para a comissão de avaliação. Das 1068 avaliadas, 861 foram coletâneas, ou obras coletivas com mais de 2 autores. Apenas 207 foram autorais (1 ou 2 autores).A distribuição das obras pelos estratos pode ser observada na figura 18:

Fig.18. Distribuição dos livros por tipo e estrato. Classificação do triênio 2010/2012.

\begin{tabular}{|c|c|c|c|c|c|}
\hline \multicolumn{2}{|c|}{ Autoral } & \multicolumn{2}{c|}{ Coletânea } & \multicolumn{2}{c|}{ Total (Col. + Autoral) } \\
\hline L4 & 94 & L4 & 73 & L4 & 167 \\
\hline L3 & 88 & L3 & 206 & L3 & 294 \\
\hline L2 & 14 & L2 & 410 & L2 & 424 \\
\hline L1 & 11 & L1 & 172 & L1 & 183 \\
\hline LNC & 49 & LNC & 169 & LNC & 218 \\
\hline
\end{tabular}

Como resultado, aproximadamente $40 \%$ das obras avaliadas obteve pontuação que as remeteram às menções L3 e L4, ou seja, foram consideradas altamente qualificadas. As demais, ainda que contribuam de alguma forma para o avanço do conhecimento da área, em geral se tratavam de obras caracterizadas por estudos de caso, abordagens descritivas sobre determinados aspectos temáticos, ou coletâneas compostas por textos diversos.

Sem dúvida, todo processo de avaliação envolve critérios passíveis de críticas, em função de alguma subjetividade e da composição dos atores envolvidos. Entretanto, os princípios adotados revelam o que as áreas das ciências humanas e sociais entendem como discriminatórios da qualidade da produção do conhecimento.

\section{CONSIDERAÇÕES FINAIS}

Ao longo do percurso de construção da Pós-Graduação na área de Geografia e seu estado da arte mais recente, com base no resultado da avaliação trienal 2010/2012 e seus principais indicadores, assinalamos alguns pontos como importantes avanços conquistados e outros como desafios a serem trilhados. Dentre as principais conquistas, destacamos:

a 
- A mudança da metodologia de reuniões do Conselho Técnico da CAPES, com a participação de todos os coordenadores de área nas discussões e decisões deste órgão colegiado.

- A mudança de avaliação continuada para seminários de acompanhamento por área, ao longo do triênio, com a possibilidade de discussão e construção dos critérios e pontuação do roteiro de avaliação e indicadores com os coordenadores dos programas, bem como dos critérios dos qualis periódicos e da avaliação/ classificação dos livros.

- A manutenção das visitas a todos os programas da área de Geografia. Apesar do desestímulo e restrições apresentadas pela CAPES, a área não abriu mão deste procedimento como importante instrumento no processo de avaliação.

- O aperfeiçoamento na avaliação do item produção por meio: a) produção qualificada (5 produtos); b) qualis periódico com a inclusão da ficha de avaliação, da consulta à comunidade e do fator de impacto; c) avaliação/classificação dos livros por meio do sistema de cadastramento das obras online realizado por cada programa.

Como os principais desafios, assinalamos:

- O crescimento dos programas na área de Geografia e sua interiorização, tendência esta apresentada nos três últimos triênios. O desafio refere-se da expansão commelhoria da qualidade das teses e dissertações e da sua produção intelectual em geral para a sociedade, refletida na publicação de livros, capítulos de livros e artigos qualificados.

- O enfrentamento da questão dos mestrados profissionais que, para boa parte das áreas, já se põe como uma realidade acadêmica e necessária, mas para a área de Geografia ainda é incipiente a iniciativa dessa modalidade de pós-graduação. Desse modo, precisamos acumular mais discussão para que a área tenha a capacidade/discernimento para se posicionar sobre o tema e se dispor a apresentar novos projetos nessa modalidade de curso, uma vez que uma das coordenações adjuntas da área de geografia na CAPES no presenteabarca exatamente os mestrados profissionais, com especial estímulo ao ensino de geografia, a saber, o PROFGEO.

- A garantia de uma representação no CTC que se coloque como sujeito político e mediador entre as demandas da comunidade, isto é, a área de Geografia, e as ações políticas do governo federal, do MEC e da Capes. O grande desafio que se coloca é que, cada vez mais, um número menor de docentes com maior experiência profissional e 
acúmulo acadêmico e intelectual na área se dispõe a assumir este tipo de representação e ocupar este lugar estratégico. Por outro, os docentes e colegas dos programas mais novos se veem, ao contrário, com pouco acúmulo e inibidos a se lançar e participar da coordenação de área e da comissão de consultores ad doc.

\section{REFERÊNCIAS}

1. CÓRDOVA, R. et ali. A pós-graduação na América Latina: o caso brasileiro. Brasília: UNESCO/CRESALC - MEC/SESU/CAPES, 1986.

2. CONTEL, F. B. As Divisões Regionais do IBGE no século XX (1942, 1970 e 1990). Terra Brasilis. Nova Série, n. 3, 2014.

3. CURY, C. R. J. “Quadragésimo ano do parecer CFE n 977/65”. Revista Brasileira de Educação, ANPED, n. 30, p.7-20, set/dez - 2005.

4. IANNI, O. Estado e Planejamento Econômico no Brasil (1930-1970). Rio de Janeiro: Civilização Brasileira (3ª ed.). 1979.

5. INSTITUTO BRASILEIRO DE GEOGRAFIA E ESTATÍsTICA (IBGE). Censo Demográfico de 2010.

6. CAPES - Coordenação de Aperfeiçoamento de Pessoal de Nível Superior. Relatório Final da Área de geografia - Trienal 2010-2012. Outubro de 2013.

7. SILVA, J.B. e OLIVEIRA, M.P., A trajetória da pós-graduação no Brasil e a ANPEGE: algumas questões. Revista da ANPEGE, n.5, 2009.

8. SOUZA, S. Z. L. Diferentes Visões sobre a educação. Educação Pública. Avaliação Formativa: Revendo decisões e ações educacionais. http://www.educacaopublica.rj.gov.br/oficinas/ed_ ciencias/avaliacao/avaliacao_historia02.html, acesso em 21/04/2015.

9. Site: http://www.geografia.fflch.usp.br/posgraduacao, acesso em 31/03/2015. 